\title{
CURRENT STATUS OF DEEPWATER OIL SPILL MODELLING IN THE FAROE-SHETLAND CHANNEL, NORTHEAST ATLANTIC, AND FUTURE CHALLENGES
}

Alejandro Gallego ${ }^{a *}$, Rory O’Hara Murray ${ }^{a}$, Barbara Berxa ${ }^{a}$, William R. Turrell ${ }^{a}$, CJ Beegle-Krause ${ }^{b}$, Mark Inall', Toby Sherwin ${ }^{c}$, John Siddorn ${ }^{d}$, Sarah Wakelin ${ }^{\mathrm{e}}$, Vasyl Vlasenko ${ }^{\mathrm{f}}$, Lars R. Hole ${ }^{\mathrm{g}}$, Knut Frode Dagestad $^{\mathrm{g}}$, John Rees ${ }^{\mathrm{h}}$, Lucy Short', Petter Rønningen ${ }^{\mathrm{b}}$, Charlotte E. Main ${ }^{\mathrm{j}, \mathrm{k}}$, Sebastien Legrand', Tony Gutierrez $^{\mathrm{m}}$, Ursula Witte ${ }^{\mathrm{n}}$ and Nicole Mulanaphy ${ }^{\circ}$.

${ }^{a}$ Marine Scotland Science

${ }^{\mathrm{b}}$ SINTEF

${ }^{\mathrm{c}}$ Scottish Association for Marine Science

${ }^{\mathrm{d}}$ Met Office

${ }^{e}$ National Oceanography Centre - Liverpool

${ }^{f}$ Plymouth University

${ }^{g}$ Norwegian Meteorological Institute

${ }^{\mathrm{h}}$ Centre for Environment Fisheries and Aquaculture Science

' Oil Spill Response Limited

${ }^{\mathrm{j}}$ National Oceanography Centre - Southampton

${ }^{k}$ University of Southampton

' Royal Belgian Institute of Natural Sciences

${ }^{\mathrm{m}}$ Heriot Watt University

${ }^{\mathrm{n}}$ University of Aberdeen

${ }^{\circ}$ RPS ASA

* (corresponding author) a.gallego@marlab.ac.uk. 375 Victoria Road, Aberdeen AB11 9BD, SCOTLAND

\section{ABSTRACT}

As oil reserves in established basins become depleted, exploration and production moves towards relatively unexploited areas, such as deep waters off the continental shelf. The Faroe-Shetland Channel (FSC, NE Atlantic) and adjacent areas have been subject to increased focus by the oil industry. In addition to extreme depths, metocean conditions in this region characterise an environment with high waves and strong winds, strong currents, complex circulation patterns, sharp density gradients, and large small- and mesoscale variability. These conditions pose operational challenges to oil spill response and question the suitability of current oil spill modelling frameworks (oil spill models and their forcing data) to adequately simulate the behaviour of a potential oil spill in the area. This article reviews the state of knowledge relevant to deepwater oil spill modelling for the FSC area and identifies knowledge gaps and research priorities. Our analysis should be relevant to other areas of complex oceanography.

Keywords: Oil spill; modelling; deepwater; Faroe-Shetland Channel; Northeast Atlantic

\section{Introduction}

\subsection{Oil exploration and production west of the Shetland Islands}

Oil production in deep water prospects west of Shetland (Fig. 1a) has taken place for over 20 years. The Schiehallion field (water depth 350-450 m) has been in operation since 1993, while the Foinaven field $(400-600 \mathrm{~m})$ started production in 1997. The search for new fields has consistently 
moved west towards deeper water and has led to oil exploration and discovery beyond the margins of the continental shelf, into the depths of the Faroe-Shetland Channel (FSC). For example, the Rosebank prospect (2008) is in 1,100 m, the Cambo prospect (2009) in 1,090 m and the North Uist prospect (2012) in just under $1,300 \mathrm{~m}$. This move towards deeper water exploration or production is not unique to this area. For example, in Europe similar patterns are evident on the Norwegian Continental Shelf, the Irish Atlantic Margin and nearby areas (e.g. Rockall Basin) and further afield (Eastern Mediterranean). Worldwide, Brazil, USA, Angola and Norway currently dominate deepwater production but new developments are expanding globally in all continents.

\subsection{Background to this study and research questions}

On 20 April 2010, an explosion on the Deepwater Horizon (DWH) drilling rig initiated the catastrophic release of between 4-5 million barrels, or > 700,000 tonnes (Crone and Tolstoy (2010), Camilli et al. (2010), McNutt et al. (2012), Joye et al. (2016)) of oil into the Gulf of Mexico over an 86 day period (e.g. see Cleveland, 2013) at an approximate water depth of 1,500 m. Comparable to the Ixtoc I oil spill of 1979, DWH is considered to date the largest accidental release of oil into the marine environment (see Table I in Hoffman and Jennings (2011)).

The deeper waters west of Shetland represent the closest range of water depths to that of the DWH oil spill in the UK Continental Shelf (UKCS; those areas beyond the territorial sea over which the UK exercises sovereign rights over natural resources, not strictly speaking a continental shelf in geological terms). To put the FSC situation into context, using the figures provided by BP in the North Uist Exploration Well Environmental Statement (BP, 2011), a worst-case blowout scenario with a maximum flow rate of 75,000 barrels per day could result in the release of 860,000 tonnes of oil in the same duration of the DWH oil spill, or 1.4 million tonnes in the estimated maximum time needed to drill a relief well (140 days). However, current requirements dictate that a Capping Stack System must be on scene within days of a subsea incident. Even taking into account its actual mobilisation, deployment time and well head preparation, in the absence of unforeseen circumstances preventing its success, the likely duration of an uncontrolled release should be considerably reduced (estimated $<30$ days (Oil \& Gas UK, 2012)), although this could still result in a spill of up to 300,000 tonnes and it should be noted that capping operations may not be practicable in all conditions (e.g. extreme weather). Although hydrocarbon reserves in the FSC comprise a mixture of gas condensate and oil, the latter has been found or is expected in a number of fields, ranging from light to heavy crude oil, so a major deepwater oil spill as a result of a well blow-out is possible in the area.

The DWH oil spill sparked worldwide concern about the level of preparedness in the eventuality of a prolonged uncontrolled release of oil from a deepwater installation. In response, the UK government set up an independent review of health and safety and environmental standards for the UK offshore oil and gas regime (the "Maitland Review"; https://www.gov.uk/government/uploads/system/uploads/attachment data/file/48252/3875offshore-oil-gas-uk-ind-rev.pdf), which advised the then-UK Department of Energy and Climate Change (DECC; currently the UK Department for Business, Energy and Industrial Strategy; BEIS) to review its emergency planning guidance. Oil \& Gas UK (the UK industry body) established the Oil Spill Prevention and Response Advisory Group (OSPRAG) to provide a focal point for the sector's review of the industry's practices in the UK, in advance of the conclusion of investigations into the Gulf of Mexico oil spill (OSPRAG, 2011). OSPRAG recommended that the Oil Spill Response Forum (OSRF) of Oil \& Gas UK review and promote improved oil spill modelling both at the surface and subsea. As part of its Key Recommendations (KR), OSRF recommended (KR4) "a full review of currently available spill models and their ability to provide effective transport predictions of oil and dispersed oil from subsea wellhead releases on the UK continental shelf", and (KR5) "a trial of 
selected predictive models using a range of scenarios and operational data in order to establish the need for improved or higher resolution hydrodynamic data to ensure that models are available to effectively predict oil and/or dispersed oil fate for future incidents" (Kirby et al., 2012).

In the light of the above recommendations and in the absence so-far of a comprehensive review of the oil spill predictive modelling capability in the FSC, our article addresses the following research questions: 1) Are the oceanographic and meteorological conditions in the FSC sufficiently well understood and modelled to be used as forcing data for oil spill trajectory models? 2) Are the main oil spill trajectory models used for emergency planning and response in the FSC suitable for the conditions in the area? 3) Are there any relevant aspects of oil behaviours not sufficiently well represented in these models? Note that our primary concern is a DHW-type oil spill on a platform or well, not a major shipping incident. Although tanker incidents represent a much more prevalent, albeit declining, global source of oil spills (between $47-75 \%$ by volume in 1970-1999, against 10-23\% in the same period; Burgherr (2007)), shipping (including tanker) traffic density in our area is low and generally absent of large tankers (MMO, 2014). In that sense, our circumstances are very different from those of enclosed basins such as the Baltic Sea and the Eastern Mediterranean Sea, where heavy tanker traffic and their proximity to the coastline increase the relative likelihood of oil spills due to shipping incidents and where the chance of oil reaching large sections of the coast in short timescales (Lu et al., 2012; Alves et al., 2014, 2015) is higher.

\subsection{The Faroe-Shetland Channel and adjacent areas}

The FSC separates Shetland from the Faroe Islands, in the northeast Atlantic (Fig. 1b). It is a deep $(>1,000 \mathrm{~m})$ channel oriented in a south-westerly direction, open to the Norwegian Sea to the north ( $>2,000 \mathrm{~m}$ depth) and separated from the North Atlantic by a sill to the south, the Wyville Thomson Ridge (WTR; max. depth ca. $600 \mathrm{~m}$, min. depth $384 \mathrm{~m}$ ), which is the eastern component of the Greenland-Scotland Ridge. The Faroe Bank Channel, on the south-western side, runs between the Faroe Islands Plateau to the north and the Faroe Bank to the south and provides the main pathway for deep water overflow from the FSC to the North Atlantic, with a maximum depth of 840 $\mathrm{m}$ (the deepest connection of all along the Greenland-Scotland ridge).

Circulation in the North Atlantic is largely controlled by the influence of the Atlantic Meridional Overturning Circulation (AMOC). The northern extension of that circulation system brings warm Atlantic water towards the western European margin. The FSC has long been known as a key region for the water exchange between the Atlantic basin and the Nordic Seas (e.g. Dooley and Meincke, 1981). It is one of three gateways, together with the gap between Greenland and Iceland (the Denmark Strait) and that over the Iceland-Faroes Ridge, for warm saline Atlantic water to enter the Nordic Seas, where atmospheric cooling makes the water colder and denser. This water then travels back from the Nordic Seas along the ocean floor into the Atlantic, again through these three gaps. In addition to its contribution to the general oceanic thermohaline circulation (of which the AMOC is a key component), the transport of Atlantic water northward through the Rockall Trough and along the western European shelf edge moderates the climate in western coastal Europe (Lerwick, in Shetland, is situated at a similar latitude to Anchorage, in Alaska, but their average minimum winter temperature differs by ca. $14^{\circ} \mathrm{C}$.

Atlantic water enters the northern North Sea from the FSC, bringing nutrients and biota, thus playing a major role in influencing the marine ecosystem (Edwards et al., 2002). As a result of both direct proximity and water circulation patterns, a pollution incident in the FSC or surrounding sea areas has the potential to affect not just the waters directly adjacent to it (Faroes and Scottish Northern Isles) but also a significant part of the full Scottish core marine sector, with a Gross Value 
Added (GVA) of $£ 17,390$ million, a turnover of $£ 29,619$ million and employing in the region of 45,300 people (2007 figures from Scotland's Marine Atlas (Baxter et al., 2011)) and beyond.

\subsection{Oil spill modelling}

Trajectory Models are used to simulate the transport and fate of oil spills. Trajectory Models is the term generally used in this sector for Lagrangian Individual-Based Models (IBM; Railsback and Grimm, 2005), where particle tracking algorithms simulate the advection and diffusion of individual particles representing, generally, a given quantity of pollutant. This is not the only approach possible; see North et al. (2011) for a discussion of the comparative advantages and disadvantages of Lagrangian and Eulerian approaches. Trajectory models are forced by metocean parameters (in the first instance, surface winds and water currents), generally output by meteorological and hydrodynamic models (HDMs), as relevant. Other forcing data such as waves will also influence advection and diffusion processes and may be included in the model. The most basic oil spill models represent oil as inert particles, while more advanced models aim to replicate "weathering", i.e. physical, chemical and even biological changes to the characteristics of the oil through time, and how these may affect its behaviour through evaporation, emulsification, sinking/sedimentation, drag, biodegradation and buoyancy changes, etc. The aim of this article is not to present an in-depth review of all available oil spill models but to provide a brief introduction of those commercial and non-commercial models more widely used by industry and academia (in the wider sense, including also government-funded research institutes) in our area of interest, the FSC and surrounding waters, and identify knowledge gaps and ideas for useful future developments.

\section{Oceanography and metocean conditions}

\subsection{Basin- and wider-scale processes}

Regular oceanographic measurements in the FSC were initiated in 1893 and continue to date with few gaps in the series. The hydrographic monitoring lines across the channel and other observations carried out by Scottish, Faroese and Norwegian scientists several times per year (Fig. 1a) are the present-day realisation of this historic long time series. From the early 1990's, monitoring arrays of profiling current meters (Acoustic Doppler Current Profilers, ADCP) were established to study the long-term trend and variability in the inflows and outflows to/from the Nordic Seas. Other technologies have been deployed to supplement oceanographic observations in the area, such as drifters, gliders (autonomous underwater vehicles, AUV) and High Frequency Radar (the Brahan project; http://www.thebrahanproject.com), as well as the incorporation of satellitebased measurements (e.g. sea surface temperature and sea surface height).

The far-field forcing of the FSC oceanographic processes is driven by the far field effect of the overturning and gyre circulation of the Atlantic, the large scale north-south density gradient (warmer, less dense water to the south), large scale sea level difference between the Atlantic and Nordic Seas, and wind stress both locally within the channel and further out in the Atlantic. The general residual circulation pattern in the FSC (Fig.2; Turrell et al., 1999) is very complex. Two Atlantic water masses are present on the surface: the Slope Current transports North Atlantic Water (NAW), along the western European shelf edge into the channel, while Modified North Atlantic Water (MNAW) originates further west in the Atlantic, crosses the Iceland Faroes Ridge and then turns south into the FSC before re-circulating north. The Modified East Icelandic Water (MEIW) is an intermediate water mass that originates to the east of Iceland. A proportion of that water mass also re-circulates within the FSC and flows north, while some joins the overflow through the Faroe Bank 
Channel. Below, another intermediate water mass, the Norwegian Sea Arctic Intermediate Water (NSAIW), and the deepest water mass, the Norwegian Sea Deep Water (NSDW), enter the channel from the Norwegian Sea and overflow primarily through the Faroe Bank Channel (Hansen and Østerhus., 2007), although a small quantity flows over the WTR (Sherwin et al., 2008). This distribution of water masses (Fig. 3; Berx et al. 2013) results in a permanently stratified water column with sharp vertical density gradients. Direct (ADCP) and indirect (satellite altimetry) estimates of transport in the FSC show no long-term trends for a net transport of approximately 0.4 $10^{6} \mathrm{~m}^{3} \mathrm{~s}^{-1}$ towards the north: the balance between $2.710^{6} \mathrm{~m}^{3} \mathrm{~s}^{-1}$ of Atlantic water mass going north and $2.310^{6} \mathrm{~m}^{3} \mathrm{~s}^{-1}$ of polar water mass net transport south (Hansen and $\varnothing$ sterhus (2007), Berx et al. (2013)). However, the seasonal amplitude of the Atlantic water inflow is around $0.7-0.910^{6} \mathrm{~m}^{3} \mathrm{~s}^{-1}$, or ca. $25 \%$ of the net transport, which is maximum in winter and minimum in summer (Berx et al., 2013).

\subsection{Meso-scale processes (I) - internal tide and internal mixing}

Three tidal constituents tend to dominate the northwest European continental shelf, of which the principal lunar semi-diurnal $\left(\mathrm{M}_{2}\right)$ tide is the biggest (Cartwright et al., 1980). The principal solar semi-diurnal ( $\mathrm{S}_{2}$ with a period of 12.00 hours), and thirdly the larger lunar elliptic semi-diurnal $\left(\mathrm{N}_{2}\right)$ with a period of 12.66 hours are the other significant tidal constituents. Gould (1984) observed barotropic $\mathrm{M}_{2}$ tidal currents of $27.8 \mathrm{~cm} \mathrm{~s}^{-1}$ with the tidal ellipse directed towards $57^{\circ}$ at the southern end of the WTR, with $\mathrm{S}_{2}$ and $\mathrm{N}_{2}$ measuring 9.9 and $5.4 \mathrm{~cm} \mathrm{~s}^{-1}$ respectively. The tidal semi-major axis is therefore approximately perpendicular to the orientation of the WTR. Larsen et al. (2000) found $M_{2}$ to be the most significant tidal constituent in the region of the Faroe Plateau. A three dimensional model of the major tidal constituents in the FSC was constructed by Davies et al. (2001). This model included diurnal components $\mathrm{O}_{1}$ (principal lunar diurnal) and $\mathrm{K}_{1}$ (lunisolar diurnal). In general, then, tidal current magnitudes in the region are typically $30 \mathrm{~cm} \mathrm{~s}^{-1}$ (Mauritzen et al., 2005).

As described above, the hydrography within the FSC and across the WTR is characterised by sheared mean flow and permanent stratification. There is a strong permanent thermocline at around $600 \mathrm{~m}$ on the Shetland (eastern) side and weaker on the Faroese (western) side of the channel. Vertical excursions of the deep thermocline were first noted by Knudsen (1911) and exceeded $100 \mathrm{~m}$ in magnitude. Clear periodicity was observed in the vertical motion of the pycnocline, with primarily semidiurnal $\left(\mathrm{M}_{2}\right)$ but some diurnal influence. The steep topography of the ridge obstructs the major axis of the northeast Atlantic barotropic tidal Kelvin wave travelling north and results in the vertical displacement of water, generating internal waves at tidal frequency (an internal tide), as described by Knudsen (1911) and, more recently by Sherwin (1991), as the water aims to return to a state of equilibrium. Studies involving the internal tide in the Faroese channels have tended to focus primarily on the northern section of the FSC. A deep internal tide observed and analysed in the FSC by Sherwin (1991) was found to be consistent with generation at the $M_{2}$ frequency from the WTR. Later observations in the FSC using a microstructure shear profiler revealed patchy elevated mixing levels in the permanent deep thermocline resulting from breaking of high wavenumber internal waves (Hosegood et al., 2005). Internal wave observations made on the west Shetland slope of the FSC (Hall et al., 2011) using moored thermistors, moored ADCPs and profiling ADCP/CTD systems revealed a semidiurnal internal tide and nonlinear wave trains at the sea bed. Associated modelling work suggested a very strong external to internal tide energy flux (10 $\mathrm{kW})$, again, from the northern slope of the WTR.

The picture revealed, then, is one of intense near bed currents and shearing caused by the internal tide. The internal tide waves generated at the WTR propagate away from the source and their large amplitude (up to $100 \mathrm{~m}$ ) can be observed in temperature and current profiles (Fig. 4a). These internal waves can break as they interact with the steep (super-critical) channel slopes, 
generating areas of very high turbulent energy dissipation rates, energetic enough to re-suspend sediments (Fig. 4b) (Hosegood et al., 2004), an aspect of particular relevance to oil spills (see Section 5 ) if they have made contact with and been entrained into sediments. To make prediction of currents even more difficult, internal tides may interact with longer period processes such as eddies (see 2.3, below) and trapped low frequency waves.

\subsection{Meso-scale processes (II) - meanders, filaments and eddies}

From past studies of meso-scale processes in the FSC (e.g. Sherwin et al., 1999) the area is known as a region of high mesoscale variability $\left(>300 \mathrm{~cm}^{2} \mathrm{~s}^{-1}\right.$ at the surface; Sherwin et al., 2006), which appears to mix MNAW and NAW before they enter the Nordic Seas. Anti-cyclonic meanders of the front between these two water masses stretch to $80 \mathrm{~km}$ across the channel and have velocities of up to 0.7 to $0.9 \mathrm{~m} \mathrm{~s}^{-1}$ (Sherwin et al., 1999; Sherwin et al., 2006). They can be observed in satellite images (ocean colour (Fig. 5) and altimeter data), drifter trajectories and measurements of velocity and water properties (temperature and salinity). These meanders grow at two preferred locations in the channel (Sherwin et al., 2006) and do not seem to propagate, probably because their group velocity is effectively zero due to the underlying southward flowing deep water. Their growth time is of the order of a few days to one week and they appear to have a limiting size, below which they may disintegrate into mesoscale eddies. Evidence from altimetry indicates that eddy kinetic energy intensity varies temporally, as well as spatially, at various scales; it generally reaches a minimum in the autumn and at times of high NAO (Chafik, 2012).

\subsection{The wave and wind fields}

The prevailing winds in the FSC are from the south-west. This, combined with the warming influence of the slope current and North Atlantic Current, which bring NAW into the region, gives the FSC a relatively warm maritime climate. In addition, the climate in this area is influenced by two semi-permanent weather systems: low and high pressure systems over Iceland and the Azores, respectively (Department of Trade and Industry, 2003). This leads to a variable weather pattern in the FSC with variable wind speeds and directions. The wave climate of the region is dominated by waves from the south-west, due to the large south-westerly fetch enabling waves originating in the North Atlantic to propagate into the FSC.

In order to investigate more quantitatively the typical wind and wave climate of the region, 30 years of modelled winds and waves data from the European Centre for Medium-Range Weather Forecasts ERA-Interim reanalysis (Dee et al., 2011) archive were downloaded. Modelled data from the region $10^{\circ} \mathrm{W}-0^{\circ} \mathrm{W}$ and $57^{\circ} \mathrm{N}-65^{\circ} \mathrm{N}$ were extracted at 12 hour intervals over the time period of $1980-2009$. The horizontal resolution of the grid used was $0.25^{\circ} \times 0.25^{\circ}$ (longitude $x$ latitude). The parameters examined were: (i) east-west $(U)$ and north-south (V) components of wind velocity at 10 $\mathrm{m}$ above mean sea level, (ii) significant height of combined wind and swell waves, (iii) mean wave period, and (iv) mean wave direction. Monthly mean averages were taken over the 30 year period, and then a 30 year mean was calculated for each month in the year to produce a monthly mean climatology for the area. The climatological wave field does not vary significantly across the region, with a slight reduction in wave height and period east of Faroe extending into the FSC. There is less spatial variation in the climatological wind field, which varies little across the region. In order to investigate the temporal variation in more detail, data from the model grid point closest to the 400 $m$ deep hydrographic station at the east end on the Fair Isle - Munken (FIM, Fig. 1) oceanographic monitoring section $\left(60^{\circ} 20^{\prime} \mathrm{N}, 04^{\circ} 10^{\prime} \mathrm{W}\right)$ were examined in detail.

Figure 6 shows the results from the wind speed climatology, and confirms the south-west prevailing wind direction. The strongest winds (monthly means $14-16 \mathrm{~m} \mathrm{~s}^{-1}$ ) typically occur in 
January. Monthly maxima in January are between $17-27 \mathrm{~m} \mathrm{~s}^{-1}$. Figure 6 also shows some annual variation in wind direction, with prevailing winds occasionally from the west and north-west throughout the year, with the greatest variability outside the winter months. The greatest variability in wind direction is observed in May, with winds from the north-east not uncommon. Figure 7 shows the results from the significant wave height climatology of combined wind and swell waves at the same location. Throughout the year, the wave field is nearly always dominated by waves from the south-west quarter, with the highest monthly mean $(6 \mathrm{~m})$ and monthly maximum (up to $12.5 \mathrm{~m}$ ) significant wave heights occurring in January. During the summer months, the typical monthly mean significant wave height is $1-3 \mathrm{~m}$, with rare extremes of up to $9 \mathrm{~m}$ within the time series analysed. The wave period climatology analysis shows that the largest monthly mean wave periods (10.0 $11.5 \mathrm{~s})$ mostly occur during the winter months (Dec. - Feb.), although they can also occur during March, October and November. Typically, during the summer the wave periods are in the range $6-$ $9 \mathrm{s.}$

\subsection{Knowledge gaps and future directions}

Relevant oceanographic processes that require further investigation include horizontal dispersion, bathymetric controlled processes and interactions with the sea bed (including overflow over ridges), intermittent turbulence (particularly regarding how it can affect the initial dilution and dispersion of an oil spill close to its source) and ocean-shelf exchanges.

The degree of predictability of the processes under consideration needs to be quantified better to be able to incorporate them into models. Our understanding of the chaotic nature of the system is still relatively basic (small changes in the initial state result in big variations in outcome). Additional research is required to characterise the interactions between different processes, e.g. between the deep channel circulation and currents generated by internal tides interacting with surface currents. Specifically, the scale of these processes in oil exploration/production areas needs to be described adequately but also on a much wider geographical scale because an oil spill could quickly extend beyond these areas (see Section 4.1), covering both oceanic and coastal zones. Much of the above applies mainly to a sub-surface oil plume. Once oil reaches the sea surface, wind plays a dominant part (see below), although the mesoscale variability of surface currents in the FSC will complicate the picture.

From a practical point of view, we need good resolution, high-quality bathymetry for understanding and modelling the oceanography of the area. Another requirement, for emergency response planning purposes, is a sufficiently long time series of wind fields to capture the significant climatic scale variability that would affect oil spill trajectories, although Section 2.4 above provides a preliminary analysis. Detailed real-time wind data and accurate forecasts are critical for surface spill monitoring in an emergency response situation in order to be able to deploy the relevant resources in the right areas, warn potentially affected parties, etc. and winds are generally difficult to forecast at the scale of the movement of an oil spill. However, given the considerable distance between deepwater prospects in the FSC and adjacent shorelines, there is reasonable scope for using observational data to validate oil trajectory forecasts and direct the response effort. Wind patterns in the open waters of the FSC are less likely to be significantly complicated by processes such as orographic steering than in more enclosed basins like the Baltic or Mediterranean seas, where beaching can also take place in a much shorter timescale, but the validity of wind forecasts in our focus area has not yet been comprehensively evaluated, to our knowledge. We also need a good understanding of seasonal variability in metocean data - winter data are relatively scarce in the FSC so there is a role for new technologies (e.g. from gliders and other autonomous vehicles), complementing manned observation platforms, to acquire winter data throughout the water column. In practical terms, SST and altimetry are useful remote sensing products but additional 
remote sensing tools can be used to study the oceanography of the area. Surface sensing from satellites or radar is invaluable and must be used, as well as ferryboxes (carrying a range of sensors, including vessel-mounted ADCP) on ships of opportunity but, to assess how these surface observations represent conditions throughout the water column, we need full water column observations (from ships, moorings and AUVs) with high temporal and spatial resolution. Such survey effort needs to be carried out in collaboration between all stakeholders with an interest in the area, i.e. the research community and industry sharing data and resources in collaborative projects such as SERPENT (http://www.serpentproject.com), which uses oil and gas downtime and opportunistic Remotely Operated Vehicle (ROV) observations to gather scientific environmental data. Real-time observations are required for data assimilation in models, and this is another potential area for collaboration with industry (e.g. locating instruments and sensors in offshore oil and gas infrastructure).

\section{Hydrodynamic modelling}

\subsection{General model availability covering the FSC}

Oil spill models need to be forced with ocean current data. In tidally dominated regimes, gridded harmonics data can be used to reconstruct a representation of the total current and, in other regions or for contingency planning purposes, climatological currents could be used. However, as the effects of the actual meteorological conditions are missing in both approaches, this may lead to significant discrepancies if trying to model specific events, especially in circumstances of extreme weather. Operational hydrodynamic model (HDM) data are therefore required to provide currents forcing for oil spill models when used for emergency response, although there are emerging alternatives for short-term predictions (e.g. Abascal et al., 2009; 2017) and new advances in trajectory modelling using aspects of chaos theory can detect earlier where major changes will occur in the surface expression of an oil spill and identify areas where an oil spill is unlikely to reach (Olascoaga and Haller, 2012, Allshouse et al., 2017). HDM data can also be used to characterise the density structure of the water column, where required (in all but the most basic models), and for some biological processes, where other factors such as salinity and temperature are also important. As we noted above, in relation to oil spill modelling, OSRF recommended "to establish the need for improved or higher resolution hydrodynamic data" (Kirby et al., 2012). In response to the DWH oil spill in the Gulf of Mexico, the US accelerated the development of systems for provision of HDM model products, with evaluation of metrics of relevance to oil spill response demonstrating the potential value of HDMs (Zaron et al., 2015).

Although our focus area is the FSC and its adjacent waters, given the time it may potentially take to stop the flow of oil (as was the case in the DWH oil spill), and the potential persistence and coverage of an oil spill in the marine environment (see section on long-term simulations below), this requires a considerably wider spatial domain of the selected HDM for simulations beyond the shortterm response. In this article, we will consider regional and basin scale but not global scale HDMs.

Most models can be run in reanalysis or hindcast mode to produce historical time series and climatologies. Both are useful for planning/preparedness and to analyse historic incidents. However, to be useful for emergency response (particularly beyond the immediate short-term aftermath of an incident) models need to be run in real-time operational mode, including forecasts. Basin scale operational models have currently achieved very reasonable resolutions (of the order of tens of kilometres) and make use of advanced data assimilation schemes but they often do not incorporate tidal processes and their vertical co-ordinate systems are often less than ideal to deal with the steep bathymetry gradients observed beyond the open ocean (such as on the shelf break, 
continental shelf and coastal areas). This is important for resolving adequately vertical currents and other processes contributing to vertical velocities (e.g. internal waves). When combined with oil droplet vertical rise velocity, these will determine the height of any subsequent midwater plume and the timing and location of a surface slick, which can also impact on the safety exclusion zone for responders. Overall, it is clear that basin scale model resolution is generally too coarse to resolve adequately or at all the important meso- and finer-scale features that characterise oceanographically complex areas such as the FSC. Basin scale models, however, are critical providers of boundary conditions for regional scale operational models. A list of basin scale models that incorporate our area of interest is provided in Table 1. Regional scale operational HDMs are generally eddy-resolving and have a more appropriate resolution but they often have more limited data assimilation capabilities, although a number of groups are now significantly advancing data assimilation capability in these systems (e.g. Zijl et al., 2015; Kourafalou et al., 2015) and, over the coming few years, this disparity will be significantly reduced. Careful analysis of model results and their validation against observations show that the choice of model should take into consideration whether all relevant processes are included (tides, topographic interactions, internal waves, etc.), the model's data assimilation scheme and its operational forecast cycle and robustness. However, some aspects of model validation which may be of particular interest in our focus area (e.g. validation against deep currents) are generally less established.

\subsection{Model development and operational implementation in the UK}

The Met Office is responsible for the main UK operational regional HDM service provision that covers the FSC area, using the Forecasting Ocean Assimilation Model (FOAM) Atlantic Margin Model (AMM7, $7 \mathrm{~km}$ horizontal resolution, and terrain-following vertical co-ordinates; Fig. 1b) (O'Dea et al., 2012). Atmospheric forcing is provided by the Met Office global Unified Model (ca. 17 $\mathrm{km}$ horizontal resolution). FOAM AMM7 model output is available via the Copernicus Marine Environment Monitoring Service (CMEMS) portal (http://marine.copernicus.eu), as well as directly from the Met Office. Development of these operational systems is done under Joint National Oceanography Centre (NOC) - Met Office research programmes (as part of the Natural Environment Research Council NERC/Met Office Joint Weather and Climate Research Programme, JWCRP). Coordination of the science in this area is being developed under the National Partnership for Ocean Prediction (NPOP).

The National Oceanography Centre, often in collaboration with the Met Office, have developed a suite of regional models of varying resolution covering the area of interest, which include POLCOMS: AMM $12 \mathrm{~km}$ (Wakelin et al., 2009) and HRCS $1.8 \mathrm{~km}$ (Holt and Proctor, 2008); and NEMO: AMM 7 (O'Neill et al., 2012) and NNA 1/12 . These are not run operationally by NOC but realistic or idealised forcing is applied for meteorological forcing, tides, open ocean boundary and freshwater input (rivers), and can be coupled with other models such as wave and ecosystem models. The models are validated against hydrographic (e.g. conductivity, temperature and depth, CTD) and drifter data, and are also used to produce long-term climatologies (e.g. 45 years, Holt et al. (2009)). Experiments are carried out to investigate the effect of model formulations, such as for example the examination of the effect of atmosphere-ocean communication frequency or the spatial resolution of atmospheric forcing on significant wave height for the Irish Sea (IRS $1.8 \mathrm{~km}$ ) implementation of the POLCOMS model. Bricheno et al., (2013) demonstrated the importance of sufficient temporal and spatial resolution e.g. to accurately represent storms and their effect on the sea state.

In general, the UK operational modelling system has been subject to extensive validation, which indicates that the different resolution models capture the main observed mesoscale ocean circulation features with some improvement demonstrated in the case of the higher resolution 
versions and display a satisfactory level of skill within their forecast windows (Storkey et al., 2010). However, much of the validation effort has focused on surface features, where data are more abundant and readily available at the relevant timescales. It is considerably more uncertain whether current operational models can replicate and forecast the complex three-dimensional circulation in the FSC at the appropriate resolution to force oil spill models accurately enough in an emergency response situation. Also, beyond the open ocean, finer resolution models are required in order to determine, for example, where the oil is forecasted to beach on the shoreline. MSS has a fine resolution Finite Volume Community Ocean Model (FVCOM) implementation covering Scottish shelf and inshore waters (the "Scottish Shelf Model"; Wolf et al. (2016)) but this model has not yet operational forecasting capability.

\subsection{Model development and implementation in Norway}

The Norwegian Meteorological Institute (MET Norway) also runs operational models that cover the FSC area (Fig. 1b). These models constitute a nested model system with data assimilation based on the Regional Ocean Modelling System (ROMS), consisting of the Arctic20 (20 km horizontal resolution), Nordic4 $(4 \mathrm{~km})$ and NorKyst800 ( $800 \mathrm{~m}$; note that this model does not cover the FSC) models, forced by an operational atmospheric forecasting system (the high resolution HARMONIE 2.5 , with a domain that covers only part of the FSC, and the bigger-domain, coarser-resolution HIRLAM 8). Waves forecasting is also provided by implementing the WAM 10 model (down to $10 \mathrm{~km}$ resolution) and it includes Stokes drift. Finer resolution configurations are available for areas closer to the Norwegian coast. As in the case of UK operational models, these models have been comprehensively validated. However, in both cases the focus of the validation tends to be on surface processes so the ability of the models to capture the necessary detail required for deepwater oil spill response is questionable.

\subsection{Small-scale processes}

Even though hydrostatic models can still capture the general characteristics of mesoscale processes such as internal tides in the area (e.g. a POM implementation by Hall et al. (2011)), nonhydrostatic models are needed to re-create properly the relevant smaller scale processes observed in the FSC, such as Ekman drainage in bottom boundary layers, intense wave breaking along the sloping bottom boundary and wave-induced mixing. As part of the NERC-funded FASTNEt project (http://www.bodc.ac.uk/projects/uk/fastnet/project_overview/) University of Plymouth researchers set up and run the MITgcm model at fine resolution $(50 \mathrm{~m}$ horizontal resolution and $5 \mathrm{~m}$ vertical layers in top $40 \mathrm{~m}, 10 \mathrm{~m}$ below) and used observational data collected over two cruises on the southwest European Atlantic shelf and shelf edge. Model results (Vlasenko et al., 2014) showed a good agreement with dye patch and drifter deployments, and other data sources (moorings, gliders) (Fig. 8). The lessons from that exercise were that it was important to set correct and well justified initial and boundary conditions for the model, as well as the accurate setting of tidal forcing. Model resolution (horizontal and vertical) was critical to minimise numerical diffusion. Even at fine resolution, it was important to parameterise sub-grid mixing adequately. Non-hydrostatic modelling is not feasible for operational applications but it can be very useful to evaluate and improve the performance of operational models. As was seen during the DWH oil spill, oceanographic sampling to obtain quality temperature and salinity profiles was critical in improving the ocean model forecasts of the subsurface currents. Hence, this need should be included in response planning for a potential deepwater oil release.

\subsection{Knowledge gaps and future directions}


Many of the individual relevant processes are being currently modelled separately so there is a need for incorporating all relevant processes (e.g. bathymetric effects, waves) into a single HDM, although this may not be critical for purely oil spill emergency response situations, where decisionmaking at different scales can be informed by separate modelling of the relevant processes. In general, we need to be able to assess the time and length scales that any particular model can replicate accurately.

Any increase in model resolution should be accompanied by availability of observational data at the same (or finer) resolution (including 3-D currents), which is a challenge at sufficient spatio-temporal resolution in relatively remote areas of complex circulation, particularly using more traditional methods such as ship-borne observations. The three-dimensional aspect is particularly relevant for oil spill applications because oil particles will have their own vertical velocities depending on the local density, which need to be superimposed on the vertical velocities output by the models, while vertical velocity calibration/validation in HDMs tends to be somewhat neglected relative to horizontal velocities. Relatively new (e.g. autonomous) and remote sensing technologies should enhance in-situ data acquisition capabilities, while data types could be prioritised based on knowledge gaps and model sensitivity studies, to achieve best value per unit effort. Benchmark datasets (standard forcing and validation data) would be very useful for assessing model skill. It is also important to assess the relative value of increased resolution against its cost (e.g. in terms of data or computing requirements).

At present there is relatively little choice of operational circulation models in the area of interest and model selection by users is suspected to be largely a function of cost and, most probably, model availability and/or accessibility. An open and inclusive (i.e. beyond just academic/peer reviewed) comprehensive review/assessment of available circulation models in the area as input for oil spill models has not yet been carried out and would be very useful. Such a review should include which sub-grid scale physical processes are incorporated into each model and how. The review needs to be region-specific (in this case for the FSC and adjacent waters), as different models are likely to perform differently in different areas, and to consider model skill throughout deep (oceanic) waters, shelf edge and coastal areas. The review should focus on whether the models capture the oceanographic complexity of the area, as described in Sections 2.1 -2.3 . The outcomes of this review need to be communicated and explained to users of HDM data for oil spill modelling, and the latter need to specify their needs to HDM modellers so that oceanographic models provide the relevant forcing data to oil spill models; in other words, what is the sensitivity of oil spill models to hydrodynamic forcing?

Notwithstanding that different HDMs require different forcing data, standardisation of model inputs and outputs (e.g. by using NetCDF CF Conventions) is now common and is important to facilitate inter-model comparisons and the wider exchange of forcing data and model output. The concept of interoperability, which includes but goes beyond standardisation, is captured in the Common Operating Picture concept referred to in section 4.3. Model ensemble runs should be used more widely to quantify uncertainty, both multi-model ensembles (different models using the same forcing data) and single-model ensemble runs with parameter perturbation (one model with forcing data variability). New HDMs should incorporate high quality real-time data assimilation capability, including "local" assimilation e.g. in areas where a spill is present, from a wide range of sources e.g. satellite and radar remote sensing, AUVs and ideally moored instruments transmitting data in nearreal time. Real time (or near-real time) data assimilation is important to improve model skill, as shown in the DWH oil spill (Zaron et al., 2015) so having in place the appropriate mechanisms to acquire and assimilate relevant data in advance of any emergency situation is highly desirable. To that effect, and to compile comprehensive hindcast datasets, government scientists, academia and industry need to interact more closely and explore the possibility to work collaboratively. In the 
context of emergency planning, HDM output datasets have been acquired by industry (e.g. in the USA and UK). In the UK, Oil \& Gas UK acquired for its members in 2014 daily flowfields from HYCOM (2009-2014) and FOAM AMM7 (2011-2014, plus hourly tides, with accompanying wind data) for the UKCS. There is also a lot of industry-owned data (e.g. ADCP), which would be invaluable to validate the models.

In practical terms, access to a suitable national or European instrument pool, accurately inventoried, in the case of an oil spill would be desirable for providing data for model assimilation or validation, in addition to monitoring the effectiveness of the response (SMART workgroup, 2006) or assessing the post-incident environmental or socio-economic impact (Law et al., 2011). Such initiative has already been actioned by the UK industry body Oil \& Gas UK. Industry support would also be welcome when scientists put forward to their funding bodies the case for further circulation model development. Although operational modelling (daily forecast cycle and longer range forecasts) is very important in an emergency response situation, it must be noted that a considerable body of observational evidence is generally required for forecasting operationally and this may not be always feasible or necessary for other applications, such as planning, where a statistical modelling approach may suffice, although it still needs to be based on a good understanding of the relevant processes. Model hindcasts and statistical approaches are also relevant not just for model evaluation purposes but also for more direct industry applications such as emergency planning and preparedness, where they are extensively used, and can even be used for actual emergency response, as it was the case in the DWH oil spill (Barker, 2011).

\section{Oil trajectory modelling}

As stated above, our objective is not to provide a comprehensive review of commercial and non-commercial oil spill models but to present a brief overview of the main models used in our focus area and adjacent waters.

\subsection{Non-commercial particle tracking schemes and oil spill models}

Research organisations (academic institutions, publicly funded research institutes, etc.) are often reluctant to use commercial oil spill modelling software. Cost may play an important part, as there are generally significant costs associated with commercial packages. Although some organisations provide free research licences for collaborative work, the general lack of accessibility to the underlying code for review and/or modification, and other issues such as the proprietary nature of oil chemistry data restrict their usefulness as research and development tools. As a result, many such organisations opt for in-house solutions or open source software.

Particle tracking algorithms are fairly standard modules, compatible with or part of most regional or larger scale HDM systems. For example, output from the NEMO model can be used offline to simulate the transport of neutrally buoyant particles with the ARIANE algorithm (Blanke and Raynaud, 1997) and thus be applied to study current flows in the model either forward or backward in time. A series of experiments with NEMO v3.2 (1/12 horizontal resolution) five dayaveraged ocean velocity fields were carried out to investigate temporal patterns in pathways and potential extent of basin scale transport of dissolved or neutrally-buoyant subsurface oil plumes originating from a release in the FSC (Main et al., 2017). Resulting trajectories were decayed in relation to model ambient temperatures to simulate biological degradation of oil in the simulated plumes, terminating their progress when particles reached (an arbitrary) $10 \%$ of their initial 'whole' state. Drift trajectories of undecayed particles allowed to drift for a whole year showed that they could cross the north Atlantic towards Greenland and most of the Norwegian coast, all the way to 
Spitzbergen. When biological decay was considered, the trajectory lengths of particles were greatly reduced (Fig. 9) but could be traced to within $200 \mathrm{~m}$ of the seabed (and therefore theoretically result in fallout of oil from the simulated plumes) over large geographical areas of the FSC, west into the Iceland basin (mainly for deeper releases) and along the shelf edge break in the Norwegian Sea (for shallower releases). Of course, the representation of oil decay in the simulations only crudely reflected actual biological degradation processes, and ignored the chemical and physical processes that would also be expected to influence or limit the persistence of sub-surface oil plumes. It did not consider, either, the threshold sensitivity to end receptors such as habitats and species. Although these simulations were not intended as a realistic representation of the fate of an oil spill, the results demonstrated the degree of potential connectivity at the basin scale and provided useful insights into other aspects such as the effect of plume depth and temporal variability (particularly interannual, over the 16 year period, 1994 - 2009 for which the experiments were run).

MET Norway can also carry out oil spill simulations (Jones et al., 2016) using the output of their coupled operational model system and an open source drift model (OpenDrift; https://github.com/OpenDrift/opendrift). Some of the simulations have been validated against drifters specially designed to mimic the drift characteristics of oil (Fig. 10) and showed a better correlation between the drifters and simulations when using the output of the finer resolution HDMs (unpublished data).

MSS use standard output from FOAM AMM7 (accessed via the CMEMS portal) and wind forecast data from NOAA's (the US National Oceanic and Atmospheric Administration) National Weather Service Wave Watch III model as standard forcing data for the General NOAA Operational Modelling Environment (GNOME v.1.3.9, the latest supported general release version at the time of this article) oil spill model, which is only able to simulate surface spills.

The North-west shelf Operational Oceanographic System (NOOS; http://noos.eurogoos.eu/), a group of 24 institutes from the 9 countries bordering the Greater North Sea that is part of the European Global Ocean Observing System (Euro-GOOS), has a Working Group on Drift where 11 oil spill models ( 8 "in house", 3 commercial) are operated by 10 member institutes. Most of these models simulate the oil spill advection and diffusion in three dimensions under the influence of the currents, wind, waves and turbulent mixing. They also compute oil weathering, oil entrainment in the water column and oil resurfacing. Although not specifically focused on deep sea applications or our focal area west of Shetland, the working group is a central point for collaboration initiatives to improve drift model forecast accuracy. The use of so many different models, each with different mathematical and numerical formulations, physico-chemical parameterizations, oil databases, metocean forcing and operational constraints, provides a useful stage for model validation (against incidents or other observational data such as drifters) and inter-model comparisons, exchanging ideas on latest developments and identifying future challenges.

\subsection{Commercial oil spill models}

As well as non-commercial models, commercial oil spill models have been available for a long time and various reviews and inter-comparison exercises have been published (Reed et al., 1999; Socolofsky et al., 2015). Over time, commercial oil spill models develop to incorporate new knowledge, new models become available and others are discontinued.

Up to recently, the Oil Spill Information System (OSIS), developed by BMT ARGOSS (Leech et al., 1993) had been the model of choice by UK governmental primary responders (the Maritime and Coastguard Agency, MCA). This commercial oil spill model has been used extensively worldwide and particularly within the UK continental shelf and has historically been widely accepted by the UK 
regulator (at the time, the Department for Energy and Climate Change, DECC). The model is no longer being developed or marketed by BMT ARGOSS and, although it continues to be used in consultancy work, it has been clearly superseded by the models briefly described below, so we are only describing it here to illustrate a change in the preferred commercial oil spill modelling software over a relatively short timescale. OSIS was built upon over 25 years' laboratory and real-life incident data. Spill advection is forced by currents, waves and wind effects. Diffusive processes (vertical and horizontal) are parameterised as a function of environmental parameters and stochastic random walk effects. OSIS also accounts for a number of oil weathering processes (evaporation, spreading, natural dispersion, emulsification and beaching). Like most oil spill models, OSIS can be used for what is termed "deterministic" (specified set of weather conditions, e.g. constant wind speed from a given direction) and "stochastic" simulations (when a wind rose or wind time series is used to produce a probabilistic output). Although the archived output of deterministic simulations can be useful in immediate oil spill response, these are generally only used for that purpose until access to model forecasts becomes available. Among its perceived advantages, OSIS is quick to run and simple to use. However, OSIS cannot model sub-surface releases and there is no subsurface weathering or water column entrainment, which make its applicability in the deep waters of the FSC limited. The model uses a fairly simplistic currents database and suffers from some technical limitations (model run duration limited by temporary run file sizes).

The Oil Spill Contingency and Response (OSCAR) model (developed by SINTEF; Reed et al., 1995; 2001; 2004; Price et al., 2006), which is part of the Marine Environmental Modelling Workbench (MEMW), simulates the 3-dimensional advection, dispersion and weathering of oil. Oil transport is forced by currents, wind, waves, diffusion and buoyancy forces. The characteristics of the oil change with time as a result of weathering and physical processes such as evaporation, emulsification and natural dispersion of its constituent hydrocarbons. These processes are modelled by accounting for the different chemical properties of more than 25 hydrocarbon component groups. Biotransformation is simulated using $1^{\text {st }}$ order kinetics (Brakstad et al., 2015a) and microbial community succession during biotransformation (Brakstad et al. 2015b). Intervention measures such as mechanical recovery or the use of dispersants (sub-surface as well as on the surface) can also be simulated by the model (Johansen et al., 2013; 2015), as well as downstream effects such as biological effects (the latter modelled by DREAM, the Dose-related Risk and Effects Assessment Model component of MEMW). OSCAR is currently widely used by the offshore oil and gas industry and regulators. Some areas of active research towards the future development of the model, of relevance to FSC conditions, are oil-sediments interactions, oil-waves interactions, long term weathering of oil and biological impacts. Other areas such as data assimilation, the quantification of uncertainty and model sensitivity within the modelling system are of general interest to the development of most oil spill models.

OILMAP (developed by RPS ASA; Spaulding et al., 1992; RPS, 2016) is another major commercial oil spill model widely used by the industry, although to the best of our knowledge it does not appear to be so widely used in the countries that border our focus area. However, it is used by some major operators and the UK MCA have adopted OILMAP as the replacement oil spill model for OSIS as part of their emergency response toolkit. Within the OILMAP suite of modules, OILMAPDeep is a deepwater blowout model that simulates the near-field behaviour of the oil. OILMAP is part of the Integrated Oil Spill Impact Model System (SIMAP). This suite of models can simulate the subsequent (far-field) fate of the spill and other downstream processes such as biological/environmental effects. OILMAP also incorporates weathering and intervention effects, including dispersant application on the surface and sub-surface.

\subsection{Knowledge gaps and future directions}


A few technical issues under consideration in oil spill modelling include wave data and wave parameterisations within oil spill models (e.g. breaking waves and whitecaps affecting the breakdown of oil droplets), the incorporation of freshwater effects (where relevant, such as in coastal areas), the fate and effect of dispersants (including subsurface applications) and oil/dispersant interactions, the need for a correct understanding of how the properties of oil may change in response to different conditions (in the field and not just in the laboratory) and how this aspect can be adequately incorporated into the models. Although weathering studies to incorporate these processes in models (e.g. NOAA's ADIOS or SINTEF'S OWM) have been carried out in the past, this is still a highly active area of research. In particular, the effect of chemical dispersants has received considerable attention since sub-surface application at the wellhead was carried out operationally for the first time during the DWH oil spill (Atlas and Hazen, 2011).

Forcing data (e.g. from HDM output) can be difficult to acquire, extract and reformat for input into the spill models. Hence, high quality and user friendly data tools need to be developed; although most oil spill models will nowadays read standard HDM output formats (such as netCDF), some are more efficient with their proprietary formats and the extraction of the relevant spatial and temporal subsets from what are often large output datasets can still be challenging. We should aim towards standard model inputs and outputs (when modelling both as part of the regulatory process and in emergency response situations), both in terms of parameters and formats. Standardisation would facilitate the use of different models best suited to specific circumstances, as well as intermodel comparisons, although for the latter this may not be sufficient as different models may not be able to use exactly the same initial conditions (see Socolofsky et al., 2015).

Data need to be made more openly available from industry, particularly during a real incident, although there may be difficulties arising from liability issues. It would also be very useful for academic/governmental model developers to have more ready standard access to industry data for improving and validating models, although we acknowledge that access to proprietary data (e.g. oil composition data) is highly problematic. There is a need for greater scenario testing, e.g. experimenting with different well depths, release pressures, testing the effect of very low temperatures (as in the bottom of FSC), etc.; a lot of the work done on these topics has struggled to reach the scientific literature, although circumstances have started to change since the DWH oil spill, which had an extensive output in the peer-reviewed literature. Models need to be carefully calibrated and, in order to achieve this, more data are required, including current profiles and other oceanographic parameters, as well as data from tracer experiments, drifters and actual past oil spills. A practical exercise like an artificial oil spill (or tracer experiment as a less realistic alternative) would be useful, both to test observational monitoring effectiveness and the models' forecasting skill. A similar exercise was carried out in Norway in 2000 (DeepSpill; Johansen et al., 2001) but the oceanographic conditions of the area were different, which would have an effect on the behaviour of the spill (including critical aspects such as the formation of gas hydrates). In addition, both observational and modelling technologies have advanced considerably since that experiment was carried out. Nevertheless, a robust methodology for testing model output against actual oil releases is still needed, as hindcasting real events is generally very useful for model validation.

In reality, although there are many oil spill models available, increased choice and competition should stimulate further modelling advances. Therefore, the development of new models is desirable in principle, as well as the enhancement of existing ones. Although more direct involvement of the active academic community is useful, it is important that models are capable of effective operational output, in addition to research applications. More specifically to our area of interest, we have seen that the FSC is a very complex area. Although it is likely that the main limitation of oil spill modelling in the area is the adequateness of HDM forcing, there is a need to focus on oil model evaluation for specific areas, similarly to what is required for HDMs. A tracer (see 
Ledwell et al. (2016) in the Gulf of Mexico) or experimental spill experiment like the one mentioned above may provide a useful test dataset to that effect, while acknowledging that a chemical tracer other than oil will not test all relevant components of an oil spill model, as e.g. it will not behave, evolve or be subject to intervention measures in the same way as an oil spill. Also, it must be remembered that the suitability of a model is highly dependent on the specific application (e.g. planning, response or damage assessment/restoration; see Section 6).

Irrespective of the application, to fully assess the performance of different models, model sensitivity to input parameters and model formulations needs to be critically evaluated, a task that may be difficult in the case of commercial models where such information may not be in the public domain, even though this is becoming increasingly available in the peer-reviewed literature. Model uncertainty needs to be quantified; this is a combination of uncertainty in the input parameters and model uncertainty. Therefore, practically, we need to move towards ensemble modelling for planning and response as standard, using parameter perturbation (multiple runs of the same model using a range of parameters, forcing data, etc.) and/or running a suite of different spill models with the same forcing (MacFayden et al., 2011). As in the case of operational HDMs, the input or assimilation of real-time observational data is useful to improve the forecasting accuracy of oil spill models

There needs to be a more structured and systematic approach to how models can be incorporated into the emergency response and licensing frameworks. The concept of a "Common Operating Picture (COP)", an interoperable architecture with standardised interfaces to facilitate data sharing during incident response, is becoming widespread within industry and responders (IPIECA-IOGP, 2015), and it is important that modelling tools are well integrated into this COP. Within a COP, all relevant data become readily available to those who need them in an understandable and user-friendly format, and models, observations, and relevant and up-to-date (environmental, socio-economic, etc.) sensitivity maps are seamlessly integrated into a shared architecture to provide emergency responders with a comprehensive assessment of the present situation and appropriate forecast scenarios. Relevant data layers exist in our focus area, for example in the Marine Scotland Information portal (http://marine.gov.scot/), which also include interactive web maps available through the National Marine Plan interactive (NMPi; http://marine.gov.scot/maps/nmpi) and these data resources are well established elsewhere, such as NOAA's Environmental Sensitivity Index (ESI) Maps, which provide a concise summary of coastal resources potentially at risk. An integrated system allows a robust cost-benefit analysis of potential intervention measures to take place (e.g. see NOAA's Trajectory Analysis Planner tool (Barker and Galt, 2000)). To develop optimised COPs, it is important to evaluate which models are not just acceptable but are the best tool for the job. The environmental data field, e.g. winds and currents, will determine the relevant scale for modelling so, for example, depending on the oceanographic characteristics of a given area, a higher resolution or unstructured grid model may be needed.

Although since the DWH oil spill a greater emphasis has been placed on peer-review publication of model performance, comprehensive model suitability can still sometimes be difficult to assess because specific components of (in particular, commercial) models are treated as a black box. We should work towards at least a minimum standard or characteristic that any given model must fulfil for a particular situation (e.g. the need to be 3D, or to allow oil releases at depth). Therefore, in the short term, model inter-comparison exercises should be encouraged and facilitated: they can be expensive exercises, in terms of staff resource, requiring adequate funding. Some work of relevance to our focus area is already underway (e.g. by the NOOS WG on Drift, or some initiatives commissioned by the UK industry body Oil \& Gas UK). We may need to wait until the end of ongoing analyses before deciding whether a more comprehensive and wide-ranging review is needed, perhaps focusing on our area of interest, possibly funded by government and 
involving all relevant experts in all relevant fields. To that effect, it is critical that any review or intercomparison exercise addresses the key questions that would need to be answered during an oil spill in our region, so that the models are improved for decision-making during an emergency response.

In terms of communication, we need to promote wider cross-disciplinary discussion, including a vehicle for wider community involvement to help inform decisions during a real-life response. During an emergency, expert knowledge is required to parameterise models, esp. as there is often a lack of hard data (e.g. exact position, oil type, release rate). However, the direct involvement of the wider community in emergency response is often problematic or impractical, as comprehensive training is important to ensure familiarity with often very complex models and even with the administrative complexities of the statutory response framework. Another big challenge for the wider community is the need for operational round-the-clock availability of modelling capability, which requires teams of well-trained experts, capable of interpreting and, if necessary, rerunning models before they can be translated into action plans and options for emergency responders.

\section{Aspects of oil behaviour not well represented in oil spill models}

Once oil enters the marine environment, its physical and chemical properties continuously change through the process known as "weathering". With the exception of the simplest particletracking models, most oil spill models take into account weathering effects at some level. The physical processes affecting the oil (evaporation, emulsification, dissolution) are relatively well studied. The behaviour of oil, gas, and oil-gas interactions at extreme depths, although incorporated in some of the main commercial oil spill models (OSCAR, OILMAP) is still the subject of active research. Chemical dispersant use is often considered, in order to disperse the oil into high-surfaceto-area droplets, ideally only after detailed Spill Impact Mitigation Analysis (SIMA; formerly known as Net Environmental Benefit Analysis, NEBA). In the event of a deepwater oil spill dispersant application at the release point can enhance the subsurface entrainment of the smallest oil droplets oil at depth within the water column, thus helping to minimise the amount of oil that reaches the surface (e.g. for human health and safety reasons such as air quality or to minimise impact to coastal ecosystems). Dispersant application accelerates biodegradation by increasing bioavailability to oildegrading microorganisms as a result of the increased surface:volume ratio of the smaller oil droplets. The physical effect of dispersants is well studied, and has been now been shown to scale up from the bench to larger scale releases (Brandvik et al., 2017). Research on the biodegradation of dispersed oil droplets has reached the level of component-specific biodegradation and oxygen consumption rates (Brakstad et al., 2017a). The propane "jumpstart" of the DWH oil spill has not been found to occur in pristine waters (Brakstad et al., 2017b). However, the subject of water column and in-sediment biodegradation (in the presence or absence of chemical dispersion), and sediment-oil interactions with and without dispersant remain an active area of research Due to concerns related to the use of chemical dispersants, mechanical dispersion methods are also being developed.

\subsection{Bacterial processes}

Hundreds of thousands of tonnes of oil enter the marine environment every year. Over $45 \%$ (over 600,000 tonnes) of that occurs naturally through seepage below the seafloor (NAS, 2003). Oildegrading bacteria oxidise and mineralise much of the hydrocarbons that constitute the oil and ultimately remove it from the environment. Remarkably, in the almost 50-year history of the oil and gas industry operating in the North Sea and surrounding NE Atlantic, we know very little about the microbiology, in particular of oil-degrading microbial populations, in these waters. Similarly, there 
was a lack of water column baseline microbiological data for the Gulf of Mexico prior to the DWH oil spill, where there is a long-established oil and gas industry and where natural oil seeps are a prevalent feature of the landscape on the seafloor.

Two opportune pre-spill water column samples collected from near the vicinity of the DWH blowout (Dubinsky et al., 2013; Yang et al., 2014) provided a much-needed baseline to assess the response of microbial community during the spill, as well as to indicate that the Gulf bacterial community had made a partial recovery towards pre-spill conditions by mid-2011 (Yang et al., 2014). $16 \mathrm{~S}$ rRNA sequencing methods revealed that, during the active phase of the spill, blooms of opportunistic bacteria responded to the mass influx of oil in the water column. The massive deepwater oil plume that formed at 1000-1300 m depth had triggered dramatic microbial shifts, notably of bacterial taxa belonging to the Oceanospirillales (termed DWH Oceanospirillales), Cycloclasticus and Colwellia that were found significantly enriched within the plume (Gutierrez et al., 2013a; Hazen et al,. 2010; Yang et al., 2014). This succession from aliphatic hydrocarbon-degrading bacteria (Oceanospirillales) to obligate degraders of aromatic hydrocarbons (Cycloclasticus) and psychrophilic hydrocarbon-degrading generalists (Colwellia) closely resembles the microbial dynamics that is typically observed in seawater following an oil contamination (Head et al., 2006).

Oil from the Macondo well also reached the sea surface in the Gulf of Mexico, forming expansive oil slicks that also triggered dramatic microbial community shifts, notably an enrichment of Cycloclasticus and, to a lesser extent, Halomonas, Alteromonas and Pseudoalteromonas (Gutierrez et al., 2013a) that are recognised for producing exopolymeric substances (Gutierrez et al., 2013b), i.e. biopolymers released extracellularly into the seawater that can behave as dispersants to facilitate the dispersal of the oil and increase its bioavailability for biodegradation. Marine biopolymers, which are largely produced by bacteria and phytoplankton, have been implicated in the formation of marine oil snow (MOS; Fig. 11) (Daly et al., 2016; Gutierrez et al., 2013b; Ziervogel et al., 2012), which was observed during the first research cruise on $R / V$ Pelican to the site of the blowout in early May 2010 and was frequently encountered around the vicinity of surface oil slicks. By June 2010, a little over a month after the onset of the spill, MOS was no longer visible at DWH, as it had sedimented to the seafloor in what is described as the "Dirty Blizzard".

During the DWH spill, more than 7 million litres of the synthetic dispersant Corexit-9500 were applied on sea surface oil slicks and directly at the leaking wellhead to promote formation of small, slow-rising droplets, and to help increase the bioavailability of the oil for microbial degradation. Recent evidence has shown that the dispersant significantly altered the microbial community of the oil plume by selecting dispersant-degrading bacteria, such as Colwellia, that bloomed in deep waters of the Gulf during the spill (Kleindienst et al., 2015). Whilst the environmental impact and fate of dispersant usage continues to be a topic of debate, its future use needs to be critically evaluated within the SIMA in order to take into account its potential effects on indigenous communities of oil-degrading microorganisms that are key to the natural attenuation process.

Current collaborative projects between Heriot Watt University and MSS are investigating the diversity, abundance and function of oil-degrading microbial populations in the NE Atlantic, including their response to dispersant applications. Hitherto, the only report investigating this for the FSC has shown that dispersants and nutrients can positively influence the formation of MOS and the microbial communities of surface waters in this region (Duran Suja et al., 2017). Laboratory experiments with FSC surface waters showed that the presence of dispersant triggers the formation of MOS, but that nutrient addition magnifies this. Using Illumina MiSeq sequencing, the microbial communities associated with MOS particles were found to be dominated by oil-degrading (Cycloclasticus, Thalassolituus, Marinobacter) and extracellular polymeric substance (EPS)-producing 
(Halomonas, Pseudoalteromonas, Alteromonas) bacteria, and included major representation by members affiliated to Psychrobacter and Cobetia with putative oil-degrading/EPS-producing qualities. In this same study (Duran Suja et al., 2017), the presence of dispersants and crude oil amended with/without nutrients resulted in the intermittent, and in some cases short-lived, bloom of opportunistic heterotrophs, principally obligate hydrocarbonoclastic (Alcanivorax, Cycloclasticus, Thalassolituus, Marinobacter) and EPS-producing (Halomonas, Alteromonas, Pseudoalteromonas) bacteria in the surface waters of the FSC. These findings in this subarctic northeast Atlantic region reflect those observed in surface waters during the DWH oil spill and provide a platform for comparison. It also opens the possibility of bioremediation strategies in oil-spill contingency to enhance the hydrocarbon attenuation process.

\subsection{Interactions with sediments}

Common oil types often have specific gravity $<1$ so they naturally float in seawater, although this is of course temperature- and pressure-dependent. Oil in the water column or on the surface can reach the sediment as a result of weathering-induced changes or after binding with material of inorganic (suspended particles, forming oil mineral aggregates, OMA) or organic (marine snow, faecal pellets, forming MOS; Passow et al., 2012) origin. These mechanisms can result in the sinking of oil in areas where recovery is not possible or practical, unlike the oiling of shoreline sediments. Studies on the fate of the 1979 Ixtoc oil spill (well blowout at $50 \mathrm{~m}$ depth) indicated that approximately $25 \%$ of the 3 million barrels of oil released settled to the bottom of the Gulf of Mexico, affecting an area of $2,800 \mathrm{~km}^{2}$ (Jernelov and Linden, 1981). Much of the research following the DWH oil spill focused on the deepwater oil plume that formed following the application of large amounts of Corexit-9500 dispersant directly at the wellhead. Despite the intense research effort, approximately 1.1 million barrels of oil were unaccounted for a month after closure of the wellhead and a large fraction of that is believed to have reached the sediments (Chanton et al., 2014). Oil contamination triggered a profound response by the sediment microbial community at the taxonomic, functional and genomic levels. However, hydrocarbon degradation was relatively slow considering the presence of high concentrations of labile $n$-alkanes 1 year after the spill. Recalcitrant PAHs in particular persisted in sediments impacted by the DWH oil spill with negative impacts on benthic fauna (Montagna et al., 2013). Based on sediment samples taken 6 months after the spill, the aforementioned study estimated $24.4 \mathrm{~km}^{2}$ of sediment were severely impacted and $148 \mathrm{~km}^{2}$ moderately impacted by DWH oil, whereas a study based on $>3000$ samples, for which data were available by 1 January 2014, identifies an area of $3200 \mathrm{~km}^{2}$ around the Macondo well as contaminated by the DWH spill (Valentine et al., 2014).

Several surveys of the Atlantic Margin area (e.g. AFEN, 2001) have characterised the prevalent sediment types in the FSC. Most of these are fine sediments (clays, muds, silt) and sands. In muddy sediments, oil will generally penetrate just below the surface, where it can persist for a long time and be available for re-suspension (e.g. Gong et al., 2014, Tremblay et al., 2005). Organic matter within the sediment matrix increases adsorption and decreases transport and biodegradation, which can also be reduced by anaerobic conditions, high pressure and very low temperatures (Gong et al., 2014, Tremblay et al., 2005). The relatively high current speeds in the deepest part of the FSC (Hansen et al., 2001) prevent the deposition of fine sediment particles, resulting in sediments with higher permeability such as sands, where pressure gradients resulting from the interaction of nearbed current, internal wave or tidal effects and sediment topography allow advective porewater flushing (Huettel et al., 2014). Porewater can be moved at rates of 10's of $\mathrm{cm} \mathrm{h}^{-1}$ to depths of $>10 \mathrm{~cm}$ (Precht and Huettel, 2004) and can supply fresh particulate organic matter to the sediment, even under conditions where hydrodynamic forces prevent gravitational settling of particles. 
The use of dispersants, which results in the formation of smaller oil droplets, increases the penetration depths of oil in coarse sediments and penetration depths for oil droplets of up to several decimetres have been predicted for shallow sublittoral sands (Zuijdgeest and Huettel, 2012). Another factor to be considered is the role of sediment bacteria in the transformation of the oil ("biotransformation"). Studies identifying deep-sea sediment hydrocarbon degrading bacteria and their capacity for hydrocarbon attenuation are rare. Most have focused on water column processes (e.g. Brakstad et al., 2015a,b; Hazen et al., 2010) and their applicability in oil spill modelling is often limited by the fact that, in many cases, the hydrocarbon degradation potential at $25^{\circ} \mathrm{C}$, rather than degradation rates at in situ temperatures, is investigated (see Gao et al., 2015, and references therein). Current collaborative projects between the University of Aberdeen and MSS are investigating the transport of oil in NE Atlantic sediments, as well as the diversity, abundance and function of oil-degrading microbial populations in the sediments of the deep NE Atlantic at in situ temperatures, and indicate a significant reduction in hydrocarbon degradation between incubations at $5{ }^{\circ} \mathrm{C}$ and $0{ }^{\circ} \mathrm{C}$ (Witte, pers. comm.). In addition, pressure affects microbial physiology, the physicochemical environment, biogeochemical process rates, and the fugacity of hydrocarbon in the environment, but this has been largely neglected in post-DWH studies. A fundamental understanding of these processes is required before they can be fully evaluated and incorporated into oil spill models.

\subsection{Knowledge gaps and future directions}

Still relatively little is known about water column processes where microorganisms play a significant role in the fate of oil, such as by degrading hydrocarbon or participating in the formation of MOS, although our knowledge has increased dramatically after the DWH oil spill (see Passow et al., 2012). More acutely, there is little knowledge on interactions/fluxes between oil and sediments, and the sediment-water interface. There are significant knowledge gaps regarding deep water sediment fauna, partly due to the great logistical challenges associated with deep water research.

Basic knowledge such as baseline and community succession studies of bacterial community structure and function in the sediment and water column need urgent attention because of a changing climate and the potential risk of acute perturbation events. An example study is Brakstad et al. (2015b). Internal mixing processes in areas like the FSC can be very intermittent, so how intermittent mixing of oil affects the dynamics of transport and degradation needs to be taken into account. This could be initially instigated in laboratory experiments and then applied to the field. The impacts of subsurface chemical oil dispersion need to be quantified more accurately, in order to understand not just their effect on the oil but their ultimate fate and effect on the ecosystem. This should also include the effect of dispersants on specific types of oil and on the microbial response, not just at source but as they weather with time (especially subsurface) and the combined effect of multiple types of dispersant. The effects of nutrients should also be taken into account, given their reported influence on the fate of oil, such as in MOS formation. Once the main knowledge gaps have been addressed, it would be necessary to investigate how the research findings can inform an effective operational response.

Further research is needed to incorporate and/or parameterise adequately the more sophisticated aspects of oil behaviour into the models (sediment interactions, biodegradation in sediments and water column, effect of dispersants/nutrients - particularly subsurface - on the above). Models that have all the relevant elements can be used to inform the debate about the benefits and drawbacks of use of dispersants, relative to other intervention measures or even natural degradation processes, better balancing the need for efficient response with sometimes longer-term environmental protection goals. However, as with all models (and more so in the case 
of the more sophisticated ones), users need the right knowledge to be able to run the models and interpret the results adequately.

In addition to research, there is an imperative requirement for long-term monitoring, both to acquire appropriate baseline data and to monitor any changes (natural, climatic or anthropogenic), such as what has been done from the T/V Exxon Valdez oil spill in Prince William Sound, Alaska, USA. For this purpose, we may need to develop new sensors and make use of new technologies, such as bacterial sensors on AUVs or ROVs.

\section{Conclusions and recommendations}

The FSC and adjacent waters are areas of highly complicated oceanography, with a complex vertical and horizontal distribution of water masses of highly contrasting characteristics, transported by strong currents. Metocean conditions (waves, winds) can also be quite extreme, which may facilitate natural weathering processes but may also hinder intervention measures. High fourdimensional (including temporal) variability, including substantial small- and mesoscale variability due to processes such as eddies, meanders, internal tide and internal waves, some of significantly chaotic nature, make it difficult to understand the physical environment and, therefore, replicate it in hydrodynamic models at the right spatial and temporal resolutions. It should also be highlighted that it is highly likely that the adequacy of HDM and wind forcing will be a critical driver of any oil spill model simulation or forecast.

Although the FSC area has been the focus of ongoing oceanographic research for over a century, it is critically important that the observational effort continues, to advance our understanding of the metocean conditions, particularly in the context of a changing climate, and is expanded to increase the spatial and temporal (e.g. in winter) coverage and resolution to resolve all processes of relevance to the fate of a potential oil spill in the area. Here, model sensitivity studies can help identify the most critical data gaps. The need for gaining basic understanding and acquiring adequate baseline data at the relevant resolution levels should not just be limited to the physical environment but also cover the chemistry and biology (across all taxonomic scales) at depth, on the continental slopes, in the water column and on the coastal and inshore waters of the land masses that surround the area. There is scope for enhancing to role of remote sensing and autonomous technologies to supplement more traditional observation methods, particularly where they can provide data, ideally in near-real time, for assimilation into models (Shay et al., 2011). The value of early and continued water column profiles, particularly for temperature and salinity was shown during the DWH oil spill, as these improved the ocean current field below main thermocline (NOAA, 2011). There is also scope for increased collaboration and data sharing between academic, governmental and industry-funded initiatives. This observational effort must be supplemented with experimental work on some specific topics relevant to emergency response to oil spills (e.g. sediments and water column biogeochemistry, oil and dispersant behaviour, and environmental sensitivities) where even the most basic information is generally insufficient. The Gulf Research Initiative requirement that all primary data be submitted to GRIIDC (https://data.gulfresearchinitiative.org/) is a positive step in this direction.

Oil spill modelling plays a role in oil spill response for 3 different purposes and the characteristics of the models need to be adequate for the specific objectives of the modelling task. In some cases, the same model may be used but for different scenarios and/or using different forcing data although, in others, totally different models or modelling approaches may be required. At least for some of these applications, model ensembles and data assimilation can also make a significant contribution by quantifying uncertainty and improving skill. 
For (1) Planning and preparedness, a statistical modelling approach is needed, with multiple (to account for various sources of variability) and potentially longer runs to quantify impacts on vulnerable receptors, including further-field. This modelling should also include response option scenarios, which are generally required by regulatory authorities. For this application, in the FSC we need a better understanding of the processes described in Section 2 and good observational yearround coverage at mesoscale and sub-mesoscale scales to improve and validate the HDMs that force oil spill models. We also require well validated metocean (including wind) forcing datasets and up to date, comprehensive sensitivity layers, building up on those referred to in Section 4.3.

For (2) Emergency response to an actual incident, a daily forecast cycle is needed. Here, "real-time modelling" plays an important role. The spatial and temporal scales modelled are much smaller (Chandler, 2012) than for (1) above, and processes acting at those smaller scales become much more relevant. For this application, data assimilation (from technologies able to provide data in near- real time) is particularly relevant, as well as the use of response option-specific models in some cases, which can be quickly evaluated by real time monitoring. Here, recent initiatives aimed at identifying assets and resources that could be pulled together in an emergency in the UKCS (see Section 3.5) need to be further integrated into the emergency exercise framework, although it is encouraging to report some recent examples of collaboration (e.g. scientific AUVs deployed collaboratively for real-time data acquisition in a statutory industry emergency exercise). In the US, NOAA most often uses custom in-house circulation modeling tools for hydrodynamic modelling at the small scales needed to accurately predict beaching along complex shoreline areas. Longer range outlooks, as in (1), are also used for longer-term/farther afield preparedness, although for a more limited range of realistic forcing scenarios. An operational example from the DWH oil spill is Barker (2011), which was used for studying the potential for the oil to reach the Atlantic Ocean.

Modelling is also used for (3) Restoration and recovery. Modelling can be integrated into/inform the post-spill monitoring activities (e.g. as per PREMIAM post-incident monitoring guidelines, Law et al., 2011; https://www.cefas.co.uk/premiam/guidelines/). Here, compatibility of oil spill models with other tools such as GIS is also important because other information layers (e.g. on potential vulnerable receptors and sensitivity layers) are still generally in those formats, even with the current focus on interoperability (see Section 4.3), although this aspect is also relevant to the COP concept used in an emergency response situation. As in (1) above, initiatives described in Section 4.3, which provide critical sources of openly available information on vulnerable receptors and other (e.g. socio-economic) sensitivities in the FSC and adjacent areas, should continue to develop in order to increase the amount of relevant information provided and to enhance their accessibility.

High quality, high resolution, ready available observational data are not only critical for our understanding of all relevant processes and for presenting a suitable baseline against which the impact of a hypothetical oil spill in the area could be assessed but, suitably standardised and accessible to the wider community, it would also provide a benchmark dataset for a comparative analysis or "model challenge" between different hydrodynamic and oil spill models. Operational HDMs in the area have generally only been comprehensively validated against surface features, where data are more abundant, so greater certainty about the skill of their 3-D forecasts is necessary for adequate response to a deepwater oil spill. The evaluation of HDMs and oil spill models could be carried out as a hindcast exercise to replicate past observational data but, in the absence of any significant oil spills in the area, it would justify an experimental controlled release of oil or a tracer (e.g. fluorescent dye, albeit accounting for differences in behaviour relative to oil), and/or the deployment of drifters that mimic the behaviour of oil, using the most up to date models and observational technology. 
Field surveys, laboratory and field experiments, model inter-comparison studies (e.g. as Socolofsky et al. (2015) but applied to our focus area) and emergency response exercises should be opened up more widely for collaboration opportunities between industry, responders, regulators and researchers (academic and government-funded). For these initiatives to occur, funding must be secured. Learning the lessons of past incidents, it has been advised that the time to develop trust and establish fruitful relationships among the public, academia, government and industry is before, not during or after any incident occurs. All those communities have a role to play in emergency response but their relative contribution and level of involvement will vary depending on which of the 3 applications described above the modelling is being used for.

Even though a lot still remains to be learned, the community has in principle all necessary elements to study the relevant physical processes that need to be incorporated into the hydrodynamic models that drive oil spill models. Oil spill models are becoming increasingly sophisticated and able to incorporate relevant biogeochemical processes that affect the fate of a spill, and new field and experimental knowledge (like the examples presented in Sections 5.1 and 5.2) will contribute further to their development. We now know how to apply models to assess their sensitivity to their formulations and parameterisation, and to quantify uncertainty. Hydrodynamic and oil spill models must be complemented with observational data from various sources (from remote sensing and in-situ manned and unmanned platforms), using standardised formats. Finally, models and data need to be integrated into a Common Operating Picture-type framework to provide planners and responders with a comprehensive integrated environment that can project forecast scenarios, including a range of possible intervention measures, onto dynamic environmental and socio-economic sensitivity layers for informed risk assessment and objective decision-making.

\section{Acknowledgements:}

Marine Scotland Science, the Science Division of the Marine Scotland Directorate of the Scottish Government, hosted a Deepwater Oil Spill Modelling Workshop on 18-19 September 2013 (Turrell et al., 2014). The workshop was attended by over 50 international experts from academia, government research institutes, consultancies and industry. This review article incorporates an updated description of the contents of the workshop presentations and subsequent discussion sessions. Authorship order beyond the fifth co-author is chronological by the order of workshop presentations. The authors (workshop organisers and presenters) would like to thank all the helpers and, in particular, the workshop participants for their contribution to discussions and, consequently, the contents of the present article. The cost of hosting the workshop and the work of the MSS authors were funded by the Scottish Government. We would like to acknowledge the useful comments of a referee.

\section{REFERENCES:}

Abascal, A. J., Castanedo, S., Medina ,R., Losada, I.J. and Alvarez-Fanjul, E. (2009) Application of HF radar currents to oil spill modelling. Marine Pollution Bulletin 58: 238-248.

Abascal, A.J., Sanchez, J., Chiri, H., Ferrer, M.I., Cárdenas, M., Gallego, A., Castanedo, S., Medina, R., Alonso- Martirena, A., Berx, B., Turrell, W.R. and Hughes, S.L.. (2017) Operational oil spill trajectory modelling using HF Radar currents: A northwest European continental shelf case study. Marine Pollution Bulletin 119(1): 336-350. 
Allshouse, M.R., Ivey G.N., Xu J., Beegle-Krause C.J., Lowe R.J., Jones N.L. and Peacock T. (2017) The impact of wind on the Lagrangian structure of the ocean surface transport. Environmental Fluid Dynamics 17: 473-483.

Alves, T.M., Kokinou, E. and Zodiatis G. (2014) A three-step model to assess shoreline and offshore susceptibility to oil spills: The South Aegean (Crete) as an analogue for confined marine basins. Marine Pollution Bulletin 86: 443-457.

Alves, T.M., Kokinou, E., Zodiatis, G., Lardner, R., Panagiotakis, C. and Radhakrishnan, H. (2015) Modelling of oil spills in confined maritime basins: The case for early response in the Eastern Mediterranean Sea. Environmental Pollution 206: 390-399.

Atlantic Frontier Environmental Network, AFEN (2001) The UK Atlantic Margin Environment Towards a better understanding. Report by Aurora Environmental Ltd \& Hartley Anderson Ltd. 78 pp.

Atlas, R.M. and Hazen, T.C. (2011) Oil biodegradation and bioremediation: a tale of the two worst spills in U.S. history. Environ. Sci. Technol. 45: 6709-6715. doi: 10.1021/es2013227

Barker, C.H. (2011) A statistical outlook for the Deepwater Horizon oil spill. in Monitoring and Modeling the Deepwater Horizon Oil Spill: A Record-Breaking Enterprise (Y. Liu, A. Macfadyen, Z.-G. $\mathrm{Ji}$ and R. H. Weisberg eds). Geophysical Monograph Series 195. American Geophysical Union, Washington, D. C. doi: 10.1029/2011GM001129

Barker, C.H. and Galt, J.A. (2000) Analysis of methods used in spill response planning: Trajectory Analysis Planner TAP II. Spill Science \& Technology Bulletin 6(2): 145-152.

Baxter, J.M., Boyd, I.L., Cox, M., Donald, A.E., Malcolm, S.J., Miles, H., Miller, B., Moffat, C.F., (Editors), (2011). Scotland's Marine Atlas: Information for the national marine plan. Marine Scotland, Edinburgh. pp. 191.

Berx, B., Hansen, B., Østerhus, S., Larsen, K. M., Sherwin, T., and Jochumsen, K. (2013) Combining in situ measurements and altimetry to estimate volume, heat and salt transport variability through the Faroe-Shetland Channel, Ocean Sci. 9: 639-654.

Blanke, B. and Raynaud, S. (1997). Kinematics of the Pacific Equatorial Undercurrent: An Eulerian and Lagrangian Approach from GCM Results. J. Phys. Oceanogr. 27: 1038-1053.

BP (2011). North Uist Exploration Well Environmental Statement. Report Number W/4123/2011.

Brakstad, O.G, Nordtug, T. and Throne-Holst, M. (2015a) Biodegradation of dispersed Macondo oil in seawater at low temperature and different oil droplet sizes. Marine Pollution Bulletin 93: 144152

Brakstad, O.G., Throne-Holst, M., Netzer, R., Stoeckel, D.M. and Atlas, R,M. (2015b) Microbial communities related to biodegradation of dispersed Macondo oil at low seawater temperature with Norwegian coastal seawater. Microbial Biotechnology 8(6): 989-998 doi:10.1111/1751-7915.12303

Brakstad, O.G., Throne-Holst, M. and Nortug, T. (2017a) Oil droplet generation and incubation for biodegradation studies of dispersed oil, in Hydrocarbon and Lipid Microbiology Protocols, Springer, Berlin, pp. 237-253. 
Brakstad, O.D., Almås, I.K. and Krause, D.R. (2017b) Biotransformation of natural gas and oil compounds associated with marine oil discharges. Chemosphere 182:555-558.

Brandvik, P.J., Johansen, Ø., Davies, E.J., Leirvik, F., Krause, D.F., Daling, P.S., Dunnebier, D., Masutani, S., Nagamine, I., Storyey, I.C., Brady, C., Belore, R., Nedwed, T. , Cooper, C., Ahnell, A., Pelz, O. and Anderson K. (2017) Subsea Dispersant Injection (SSDI) - Summary Findings from a Multi-Year Reesarch and Development Industry Initiative. International Oil Spill Conference Proceedings, May 2017, Volume 2017: 2762-2790.

Bricheno, L. M., A. Soret, J. Wolf, O. Jorba, and J. M. Baldasano (2013) Effect of High-Resolution Meteorological Forcing on Nearshore Wave and Current Model Performance, Journal of Atmospheric and Oceanic Technology 30(6), 1021-1037. doi:10.1175/JTECH-D-12-00087.1.

Burgherr, P. (2007) In-depth analysis of accidental oil spills from tankers in the context of global spill trends from all sources. Journal of Hazardous Materials 140: 245-256.

Camilli,R., Reddy,C.M., Yoerger,D.R., Van Mooy,B.A.S, Jakuba, M.V., Kinsey,J.C., Mclntyre,C.P. Sylva,S.P and Maloney, J.V. (2010) Tracking hydrocarbon plume transport and biodegradation at Deepwater Horizon Science 330: 201-204

Cartwright D. E., Edden A. C., Spencer R. and Vassie J. M. (1980) The tides of the Northeast Atlantic Ocean. Philosophical Transactions of the Royal Society of London A 298: 87-139.

Chafik, L. (2012). The response of the circulation in the Faroe Sheland Channel to the North Atlantic Oscillation. Tellus A 64: 18423, http://dx.doi.org/10.3402/tellusa.v64i0.18423.

Chandler, P.C.P. (2012) The juxtaposition of long-term and real-time oil spill modelling. In Chemical Spills and Emergency Management at Sea: Proceedings of the First International Conference on "Chemical Spills and Emergency Management at Sea", Amsterdam, The Netherlands, November 1518, 1988.. (Bockholts, P. and Heidebrink, I., eds.) Springer Science \& Business Media - Technology \& Engineering. pp.73-84.

Chanton, J., Zhao, T., Rosenheim, B. E., Joye, S., Bosman, S., Brunner, C., Yeager, K. M., Diercks, A. R. and Hollander, D. (2014) Using Natural Abundance Radiocarbon To Trace the Flux of Petrocarbon to the Seafloor Following the DWH Oil Spill., Environ. Sci. Technol., 49(2), 847-854, doi:10.1021/es5046524.

Cleveland, C. (2013). DWH oil spill. Retrieved from http://www.eoearth.org/view/article/51cbf0267896bb431f6a0797.

Crone, T.J. and Tolstoy, M. (2010) Magnitude of the 2010 Gulf of Mexico oil leak. Science 330: 634. doi: 10.1126/science. 1195840

Daly, K.L., Passow, U., Chanton, J., Hollander, D. (2016) Assessing the impacts of oil-associated marine snow formation and sedimentation during and after the DWH oil spill. Anthropocene, doi:10.1016/j.ancene.2016.01.006

Davies, A. M., Kwong, S. C. M. and Lee J. C. (2001) A detailed comparison of a range of threedimensional models of the M2 tide in the Faeroe-Shetland Channel and northern North Sea. J. Phys. Oceanogr. 31: 1747-1763 
Dee, D.P., Uppala, S.M., Simmons, A.J., Berrisford, P., Poli, P., Kobayashi, S., Andrae, U., Balmaseda, M.A., Balsamo, G., Bauer, P., Bechtold, P., Beljaars, A.C.M., van de Berg, L., Bidlot, J., Bormann, N., Delsol, C., Dragani, R., Fuentes, M., Geer, A.J., Haimberger, L., Healy, S.B., Hersbach, H., Hólm, E. V, Isaksen, L., Kållberg, P., Köhler, M., Matricardi, M., McNally, A.P., Monge-Sanz, B.M., Morcrette, J.-J., Park, B.-K., Peubey, C., de Rosnay, P., Tavolato, C., Thépaut, J.-N., Vitart, F., (2011) The ERA-Interim reanalysis: configuration and performance of the data assimilation system. Q. J. R. Meteorol. Soc. 137, 553-597. doi:10.1002/qj.828

Department of Trade and Industry (2003) Strategic Enviromental Assessment Area North and West of Orkney and Shetland.

Dooley, H.D. and Meincke, J. (1981) Circulation and water masses in the Faroese Channels during overflow '73. Deutsche Hydrografische Zeitschrift 34(2): 41-55.

Dubinsky, E.A., Conrad, M.E., Chakraborty, R., Bill, M., Borglin, S.E., Hollibaugh, J.T., Mason, O.U., Piceno, Y.M., Reid, F.C., Stringfellow, W.T., Tom, L.M., Hazen, T.C., Andersen, G.L. (2013) Succession of hydrocarbon-degrading bacteria in the aftermath of the DWH oil spill in the Gulf of Mexico. Environmental Science \& Technology, 47: 10860-10867.

Duran Suja, L., Summers, S. and Gutierrez, T. (2017) Role of EPS, dispersant and nutrients on the microbial response and MOS formation in the subarctic northeast Atlantic. Frontiers in Microbiology, (accepted).

Edwards, M., Beaugrand, G., Reid P.C, Rowden, A.A, Jones, M.B. (2002) Ocean climate anomalies and the ecology of the North Sea. Marine Ecology Progress Series, 239: 1-10.

Gao, Z-K., Yang, Y-X., Fang, P-C, Jin, N-D., Xia, C-Y. and Hu, L-D. (2015) Multi-frequency complex network from time series for uncovering oil-water flow structure. Scientific Reports 5, Article number: 8222. doi:10.1038/srep08222

Gong Y, Zhao X, Cai Z, O'Reilly SE, Hao X, Zhao D. (2014). A review of oil, dispersed oil and sediment interactions in the aquatic environment: influence on the fate, transport and remediation of oil spills. Mar. Pollut. Bull. 79(1-2):16-33

Gould, W.J . (1984) The current regime on the continental shelf North and West of the United Kingdom. SUT one-day conference "Current measurement s offshore". London 17 May 1984

Gutierrez, T., Singleton, D.R., Berry, D., Yang, T., Aitken, M.D., Teske, A. (2013a) Hydrocarbondegrading bacteria enriched by the $D W H$ oil spill identified by cultivation and DNA-SIP. The ISME Journal, 7:2091-2104.

Gutierrez, T., Berry, D., Yang, T., Mishamandani, S., McKay, L., Teske, A., Aitken, M. (2013b) Role of bacterial exopolysaccharides (EPS) in the fate of the oil released during the DWH oil spill. PLoS ONE, doi: 10.1371/journal.pone.0067717.

Hall, R. A., Huthnance, J. M. and Williams R. G. (2011) Internal tides, nonlinear internal wave trains, and mixing in the Faroe-Shetland Channel. Journal of Geophysical Research 116: C03008.

Hansen, B. and Østerhus, S. (2007). Faroe Bank Channel overflow 1995-2005. Progress in Oceanography, 75(4), 817-856. doi: 10.1016/j.pocean.2007.09.004 
Hansen, B., Turrell, W.T. and Østerhus, S. (2001) Decreasing overflow from the Nordic seas into the Atlantic Ocean through the Faroe Bank channel since 1950. Nature 411: 927-930

Hazen, T.C., Dubinsky, E.A., DeSantis, T.Z., Andersen, G.L., Piceno, Y.M., Singh, N. et al. (2010) Deepsea oil plume enriches indigenous oil-degrading bacteria. Science, 330: 204-208.

Head, I.M., Jones, D.M., Röling, W.F. (2006) Marine microorganisms make a meal of oil. Nature Reviews in Microbiology, 4: 173-182.

Hoffman, A.J. and Jennings, P.D. (2011) The BP Oil Spill as a Cultural Anomaly? Institutional Context, Conflict, and Change. Journal of Management Inquiry 20(2): 100-112. doi: $10.1177 / 1056492610394940$

Holt, J., and R. Proctor (2008) The seasonal circulation and volume transport on the northwest European continental shelf: A fine-resolution model study. Journal of Geophysical Research 113(C6). doi: 10.1029/2006jc004034.

Holt, J., Wakelin, S. and Huthnance J. (2009) Down-welling circulation of the northwest European continental shelf: A driving mechanism for the continental shelf carbon pump. Geophysical Research Letteers 36: L14602, doi:10.1029/2009GL038997.

Hosegood, P., Bonnin, J. and van Haren, H. (2004) Solibore-induced sediment resuspension in the Faeroe-Shetland Channel. Geophysical Research Letters 31(9): L09301.

Hosegood, P., van Haren, H. and C. Veth (2005) Mixing within the interior of the Faeroe-Shetland Channel, Journal of Marine Research, 63, 529-561.

Huettel, M, Berg P, Kostka JE (2014). Benthic Exchange and Biogeochemical Cycling in Permeable Seidments. Annu. Rev. Mar. Sci. 2014, 6: 23-51. Doi 10.1146/annurev-marine-051413-012706

IPIECA-IOGP (2015) Recommended practice for Common Operating Picture architecture for oil spill response. IPIECA-IOGP Oil Spill Response Joint Industry Project. 109 pp.

Jernelov, A. and Linden, O.: Ixtoc I. (1981) A Case Study of the World's Largest Oil Spill on JSTOR, Ambio, 10(6), 299-306 [online] Available from: http://www.jstor.org/stable/4312725?seq=1\#page_scan_tab_contents (Accessed 12 June 2015).

Johansen, Ø., Rye, H., Melbye, A.G. Jensen, H.V., Serigstad, B. and Knutsen. T. (2001) DeepSpill JIP Experimental discharges of gas and oil at Helland Hansen - June 2000. SINTEF Technical Report STF66 F01082. 159 pp.

Johansen, $\varnothing$., P.J. Brandvik, and U. Farooq, (2013) Droplet breakup in subsea oil releases - Part 2: Predictions of droplet size distributions with and without injection of chemical dispersants. Marine Pollution Bulletin 73: 327-335.

Johansen, $\varnothing$., M. Reed, R. Bodsberg, (2015) Natural Dispersion Revisited. Marine Pollution Bulletin 93: $20-26$

Jones, C. E., Dagestad, K. F., Breivik, Ø., Holt, B., Röhrs, J., Christensen, K. H.,,Espeseth, M.Brekke, C. and Skrunes, S. (2016). Measurement and modeling of oil slick transport. Journal of Geophysical Research: Oceans 121(10): 7759-7775. DOI: 10.1002/2016JC012113 
Joye S.B., Bracco, A., Özgökmen, T.M., Chanton, J.P., Grosell, M., MacDonald, I.R., Cordes, E.E., Montoya, J.P. and Passow, U. (2016) The Gulf of Mexico ecosystem, six years after the Macondo oil well blowout. Deep-Sea Research II 129: 4-19

Kirby, M., Aldridge, J., Barrio Frojan, C., Cook, A., Fernand, L., Greenwood, N., Grellier, K., Law, R., Lewis, A., McKie, J., Milligan, S., Moore, J., Rees, J., Righton, D., Riley, A., Sapp M. and Balaam, J. (2012) Deepwater Dispersant Use to Treat Subsea Oil Releases in UK Waters: Summary and Key Recommendations; Cefas report to Oil Spill Prevention and Response Advisory Group, no. C5464C.

Kleindienst, S., Seidel, M., Ziervogel, K., Grim, S., Loftis, K., Harrison, S., Malkin, S.Y., Perkins, M.J., Field, J., Sogin, M.L., Dittmar, T., Passow, U., Medeiros, P., Joye, S.B. (2015) Chemical dispersants can suppress the activity of natural oil-degrading microorganisms. Proceedings of the National Academy of Sciences of the USA, 112: 14900-14905

Knudsen, M. (1911) Danish Hydrographical Investigations at the Faroe Islands in the Spring of 1910. Medd. Komm. f. Havunders. Serie Hydrogr. 2(1): 21 pp

Kourafalou V.H., De Mey P., Le Hénaff, Charria G., Edwards C.A., R. He, Herzfeld M., Pascual AStanev., E.V., Tintoré J., Usui N., van der Westhuysen A.J., Wilkin J. and Zhu X. (2015) Coastal Ocean Forecasting: system integration and evaluation. Journal of Operational Oceanography 8 (sup1): 127-146.

Larsen, K.M.H., Hansen, B., Kristiansen, B. and $\varnothing$ sterhus, S. (2000) Internal tides in the waters surrounding the Faroe Plateau. ICES CM 2000/L:09. 13 pp.

Law, R.J., Kirby, M.F. Moore, J., Barry, J., Sapp, M. and Balaam, J. (2011) Pollution response in emergencies marine impact assessment and monitoring (PREMIAM) - Post-incident monitoring guidelines. CEFAS Science Series Technical Report no. 146. 164 pp.

Ledwell, J. R., He, R., Xue, Z., DiMarco, S. F., Spencer L. and Chapman, P. (2016) Dispersion of a tracer in the deep Gulf of Mexico, J. Geophys. Res. Oceans 121: 1110-1132. doi:10.1002/2015JC011405.

Leech, M., Walker, M., Wiltshire, M., Tyler, A. (1993) OSIS: A Windows Oil Spill Information System. In Proceedings of the $16^{\text {th }}$ Arctic and Marine Oil Spill Program Technical Seminar, Canada, pp. 549572.

Lu, X., Soomere, T., Stanev, E.V. and Murawski, J. (2012). Identification of the environmentally safe fairway in the South-Western Baltic Sea and Kattegat. Ocean Dynamics 62: 815-829. DOI $10.1007 / \mathrm{s} 10236-012-0532-\mathrm{x}$

MacFadyen, A., Watabayashi, G. Y., Barker, C. H. and Beegle-Krause, C. J. (2011) Tactical Modeling of Surface Oil Transport During the Deepwater Horizon Spill Response, in Monitoring and Modeling the Deepwater Horizon Oil Spill: A Record-Breaking Enterprise (Y. Liu, A. Macfadyen, Z.-G. Ji and R. H. Weisberg eds), Geophysical Monograph Series 195 American Geophysical Union, Washington, D. C.. doi: 10.1029/2011GM001128

Main, C.E., Yool, A., Holliday, N.P., Popova, E.E., Jones, D.O.B. and Ruhl, H.A. (2017) Simulating pathways of subsurface oil in the Faroe-Shetland Channel using an ocean general circulation model. Marine Pollution Bulletin 114: 315-326 
Mauritzen, C., Price, J., Sanford, T. and Torres, D. (2005) Circulation and mixing in the Faroese Channels. Deep Sea Research Part I: Oceanographic Research Papers 52(6): 883-913

McNutt, M.K., Camilli, R., Crone, T.J., Guthrie, G.D. Hsieh, P.A., Ryerson, T.B., Savas, O. and Shaffer, F. (2012) Review of flow rate estimates of the Deepwater Horizon oil spill. PNAS 109 (50): 2026020267. doi/10.1073/pnas.1112139108

MMO (2014) Mapping UK Shipping Density and Routes from AIS. A report produced for the Marine Management Organisation, pp 35. MMO Project No: 1066. ISBN: 978-1-909452-26-8.

Montagna, P.A., Baguley, J.G., Cooksey, C., Hartwell, I., Hyde, L.J., Hyland, J.L., Kalke, R.D., Kracker, L.M., Reuscher, M. and Rhodes, A.C. (2013) Deep-sea benthic footprint of the DWH blowout. PloS one, 8(8), p.e70540.

National Academy of Science (2003) Oil in the sea III: inputs, fates, and effects. National Academy of Sciences, National Academy Press, Washington, DC. 280 pp. ISBN: 0-309-50551-8.

NOAA (2011) Joint Analysis Group, Deepwater horizon Oil Spill: Review of the Preliminary Data to Examine Subsurface Oil in the Vicinity of MC252\#1, May 19 to June 19, 2010. US. Dept of Commerce. $169 \mathrm{pp}$.

North, E. W, Adams, E. E., Schlag, Z., Sherwood, C. R., He, R., Hyun, K. H. and Socolofsky, S. A. (2011) Simulating oil droplet dispersal from the Deepwater Horizon spill with a Lagrangian approach, in Monitoring and modeling the Deepwater Horizon oil spill: a record-breaking enterprise (Y. Liu, A. Macfadyen, Z.-G. Ji and R. H. Weisberg eds.), Geophysical Monograph Series 195. American Geophysical Union, Washington, D. C.. doi: 10.1029/2011GM001102

O'Dea, E. J., Arnold, A. K., Edwards, K. P., Furner, R., Hyder, P., Martin, M. J., Siddorn, J. R., Storkey, D., While, J., Holt, J. T., \& Liu, H. (2012). An operational ocean forecast system incorporating NEMO and SST data assimilation for the tidally driven european North-West shelf. Journal of Operational Oceanography, (pp. 3-17). http://dx.doi.org/10.1080/1755876X.2012.11020128

Olascoaga, M.J. and Haller, G. (2012) Forecasting sudden changes in environmental pollution patterns. PNAS 109(13): 4738-4743

O'Neill, C. K., J. A. Polton, J. T. Holt, and E. J. O'Dea (2012) Modelling temperature and salinity in Liverpool Bay and the Irish Sea: sensitivity to model type and surface forcing, Ocean Science 8(5), 903-913. doi: 10.5194/os-8-903-2012.

Oil \& Gas UK (2012) Oil Spill Cost Study - OPOL Financial Limits. Joint study commissioned by OPOL and Oil \& Gas UK. Published by Oil \& Gas UK. ISBN: 1903003799

Oil Spill Prevention and Response Advisory Group (2011) Final Report of the UK Oil Spill Prevention and Response Advisory Group. Oil \& Gas UK, London. 48 pp.

Passow, U., Ziervogel, K., Asper, V. and Diercks, A. (2012) Marine snow formation in the aftermath of the DWH oil spill in the Gulf of Mexico, Environ. Res. Lett., 7(3), 035301, doi:10.1088/17489326/7/3/035301.

Precht E and Huettel M. (2004) Rapid wave-driven advective pore water exchange in a permeable coastal sediment. J Sea Res 51 (2): 93-107. 
Price, J.M., Reed, M., Howard, M.K., Johnson, W.R., Ji, Z-G., Marshall, C.F., Guinasso Jr., N.L. and Rainey G.B. (2006) Evaluation of an oil spill trajectory model using satellite-tracked, oil-spillsimulating drifters. Environmental Modelling and Software Environmental Modelling \& Software 21(2): 258-270. DOI: 10.1016/j.envsoft.2004.04.025

Railsback S.F. and Grimm V. (2011) Agent-Based and Individual-Based Modeling: A Practical Introduction. Princeton University Press. 352 pp.

Reed, M., Aamo, O.M. and Daling, P.S. (1995) Quantitative analysis of alternate oil spill response strategies using OSCAR. Spill Science and Technology Bulletin 2 (1): 67-74.

Reed, M., Johansen, $\varnothing$, Brandvik ,P.J., Daling, P., Lewis, A., Fiocco, R., Mackay, D. and Prentki, R. (1999) Oil spill modeling towards the close of the 20th century: overview of the state of the art. Spill Science \& Technology Bulletin 5(1): 3-16.

Reed, M., I. Singsaas, P. S. Daling, L. Faksnes, O. G. Brakstad, B. Hetland, and J. Hokstad, (2001) Modeling the Water-Accommodated Fraction in OSCAR2000. Proceedings 2001 International Oil Spill Conference, pp. $1083-1091$.

Reed, M., P. Daling, A. Lewis, M. Kristin Ditlevsen, B. Brors, J. Clark, D. Aurand (2004) Modeling of dispersant application to oil spills in shallow coastal waters. Environmental Modeling \& Software, 19(7-8), Facilitating Constructive Government-Industry Interations, pp. 681-690

RPS (2016) OILMAP release notes. Version: 7.0 (July 2016). http://www.asascience.com/loginsupport/updates/oilmap/ReleaseNotes/OILMAPv7 ReleaseNotes.pdf

Shay, L. K. L. K., Jaimes, B. B., Brewster, J. K. J. K., Meyers, P. P., Mccaskill, E. C. E. C., Uhlhorn, E. E., Marks, F. F., Halliwell, G. R. G. R., Smedstad, O. M. O. M. and Hogan, P. P. (2011) Airborne Ocean Surveys of the Loop Current Complex From NOAA WP-3D in Support of the Deepwater Horizon Oil Spill, in Monitoring and Modeling the Deepwater Horizon Oil Spill: A Record-Breaking Enterprise (Y. Liu, A. Macfadyen, Z.-G. Ji and R. H. Weisberg eds), Geophysical Monograph Series 195, American Geophysical Union, Washington, D. C.. doi: 10.1029/2011GM001101

Sherwin, T.J. (1991) Evidence of a deep internal tide in the Faeroe-Shetland Channel. In Tidal Hydrodynamics. B.B. Barker, (ed.). John Wiley \& Sons (New York). pp. 469-488.

Sherwin, T.J., Turrell, W.R., Jeans, D.R.G and Dye, S. (1999) Eddies and a mesoscale deflection of the slope current in the Faroe-Shetland Channel. Deep Sea Research Part I: Oceanographic Research Papers 46(3): 415-438.

Sherwin, T. J., Williams, M. O., Turrell, W. R., Hughes, S. L. and Miller, P. I. (2006), A description and analysis of mesoscale variability in the Faroe Sheland Channel. J. Geophys. Res. 111: C03003.

Sherwin, T. J., Griffiths, C. R., Inall, M. E., \& Turrell, W. R. (2008). Quantifying the overflow across the Wyville Thomson Ridge into the Rockall Trough. Deep-Sea Research I, 55, 396-404.

SMART workgroup (2006) Special Monitoring of Applied Response Technologies v.8/2006. Edited by NOAA OR\&R Technical Information Group, 46 pp. 
Socolofsky, S. A., Adams, E.E., Boufadel, M.C., Aman, Z.M., Johansen, Ø., Konkel, W.J. , Lindo, D., Madsen, M.N., North, E.W., Paris, C.B., Rasmussen, D., Reed, M., Rønningen, P., Sim, L.H., Uhrenholdt, T., Anderson, K.G., Cooper, C,. and Nedwed, T.J. (2015), Intercomparison of oil spill prediction models for accidental blowout scenarios with and without subsea chemical dispersant injection, Mar. Pollut. Bull., 96(1-2), 110-126, doi:10.1016/j.marpolbul.2015.05.039.

Spaulding, M.L., Howlett, E., Anderson, E. and Jayko, K. (1992) OILMAP: A global approach to spill modelling. In Proceedings of the $15^{\text {th }}$ Arctic and Marine Oil Spill Program Technical Seminar, Canada, pp. 15-21.

Storkey, D., Blockley, E. W., Furner, R., Guiavarc'h, C., Lea, D., Martin, M. J., Barciela, R. M., Hines, A., Hyder, P. and Siddorn, J. R. (2010) Forecasting the ocean state using NEMO:The new FOAM system. Journal of Operational Oceanography 3(1): 3-15.

Tremblay L, Kohl SD, Rice J a., Gagné J-P. (2005) Effects of temperature, salinity, and dissolved humic substances on the sorption of polycyclic aromatic hydrocarbons to estuarine particles. Mar. Chem. 96(1-2):21-34

Turrell, W. R., Slesser G., Adams R. D., Payne R., and Gillibrand P. A. (1999), Decadal variability in the composition of Faroe-Shetland Channel bottom water, Deep Sea Res., Part I, 46(1): 1-25, doi:10.1016/S0967-0637(98)00067-3.

Turrell, WR, O'Hara Murray, R, Berx, B and Gallego, A (2014) The science of deepwater oil spills Results from the 2013 Marine Scotland Science modelling workshop. Scottish Marine and Freshwater Science 5(3): 31 pp.

Valentine, D. L., Fisher, G. B., Bagby, S. C., Nelson, R. K., Reddy, C. M. and Sylva, S. P. (2014) Fallout plume of submerged oil from DWH, 1-6, doi:10.1073/pnas.1414873111

Vlasenko V., Stashydrocarbonhuk,N., Inall, M. and Hopkins, J. (2014) Tidal energy conversion in a global hot spot: on the 3D dynamics of baroclinic tides at the Celtic Sea shelf break. Journal of Geophysical Research, V119, doi: 10.1002/2013JC009708.

Wakelin, S. L., J. T. Holt, and R. Proctor (2009) The influence of initial conditions and open boundary conditions on shelf circulation in a 3D ocean-shelf model of the North East Atlantic, Ocean Dynamics, 59. doi: 10.1007/s10236-008-0164-3.

Wolf J., Yates, N., Brereton, A., Buckland, H., De Dominicis, M., Gallego, A. and O'Hara Murray, R. (2016) The Scottish Shelf Model. Part 1: Shelf-Wide Domain. Scottish Marine and Freshwater Science 7(3), 151 pp. doi: 10.7489/1692-1

Yang, T., Nigro, L.M., Gutierrez, T., D’Ambrosio, L., Joye, S.B., Highsmith, R., Teske, A. (2014) Pulsed blooms and persistent oil-degrading bacterial populations in the water column during and after the DWH blowout. Deep-Sea Research II, http://dx.doi.org/10.1016/j.dsr2.2014.01.014

Ziervogel, K., McKay, L., Rhodes, B., Osburn, C. L., Dickson-Brown, J., Arnosti, C. and Teske, A. (2012) Microbial activities and dissolved organic matter dynamics in oil-contaminated surface seawater from the DWH oil spill site. PLoS ONE: 7 e34816.

Zaron, E., Fitzpatrick, P., Cross, S., Harding, J., Bub, F., Wiggert, J., Ko, D., Lau, Y., Woodard, K., \& Mooers, C. (2015). Initial evaluations of a gulf of Mexico/Caribbean ocean forecast system in the context of the DWH disaster. 9(4): 605-636. http://dx.doi.org/10.1007/s11707-014-0508-x 
Zijl, F, Sumihar, J. and Verlaan, M. (2015) Application of data assimilation for improved operational water level forecasting on the northwest European shelf and North Sea. Ocean Dynamics, 65(12): 1699-1716. DOI: 10.1007/s10236-015-0898-7

Zuijdgeest, A. and Huettel, M. (2012) Dispersants as used in response to the MC252-spill lead to higher mobility of polycyclic aromatic hydrocarbonsin oil-contaminated Gulf of Mexico sand. PLOS One 7(11): 1-13 


\begin{tabular}{|c|c|c|c|c|c|c|c|c|c|}
\hline \multirow[t]{2}{*}{ System } & \multirow{2}{*}{$\begin{array}{l}\text { Base } \\
\text { Model }\end{array}$} & \multirow[t]{2}{*}{ Provider } & \multirow{2}{*}{$\begin{array}{l}\text { Spatial } \\
\text { Resol'n }\end{array}$} & \multirow{2}{*}{$\begin{array}{l}\text { Output } \\
\text { Time } \\
\text { Resol'n }\end{array}$} & \multirow{2}{*}{$\begin{array}{l}\text { Shelf (S) } \\
\text { Deep } \\
\text { (D) }\end{array}$} & \multirow{2}{*}{$\begin{array}{l}\text { Atmos' } \\
\text { Forcing }\end{array}$} & \multicolumn{2}{|c|}{ Update Cycle } & \multirow[t]{2}{*}{ Notes $^{1}$} \\
\hline & & & & & & & DA & Atm & \\
\hline Nordic4 & ROMS & $\begin{array}{l}\text { Norwegian } \\
\text { Met Office } \\
\text { (MET) }\end{array}$ & $4 \mathrm{~km}$ & Daily & $\mathrm{S}$ & $\begin{array}{l}\text { HIRLAM } \\
(\sim 12 \mathrm{~km})\end{array}$ & $\begin{array}{l}\text { Twice } \\
\text { daily }\end{array}$ & $\begin{array}{l}\text { Twice } \\
\text { daily }\end{array}$ & $\mathrm{O}, \mathrm{S}, \xi, \mathrm{P}$ \\
\hline $\begin{array}{l}\text { FOAM- } \\
\text { AMM7 }\end{array}$ & NEMO & $\begin{array}{l}\text { Met } \\
\text { Office, } \\
\text { CMEMS }\end{array}$ & $7 \mathrm{~km}$ & Hourly & $S$ & $\begin{array}{l}\text { UM } \\
\text { Global } \\
(\sim 25 \mathrm{~km})\end{array}$ & Daily & Daily & $\mathrm{O}, \mathrm{S}, \xi, \mathrm{P}$ \\
\hline IBI & NEMO & $\begin{array}{l}\text { Puertos } \\
\text { del } \\
\text { Estado, } \\
\text { CMEMS }\end{array}$ & $3 \mathrm{~km}$ & Daily & $S$ & $\begin{array}{l}\text { ECMWF } \\
\text { IFS ( 16 } \\
\mathrm{km})\end{array}$ & Weekly & Daily & $O, \xi, P$ \\
\hline $\begin{array}{l}\text { Atl } \\
\text { RTOFS }\end{array}$ & HyCOM & $\begin{array}{l}\text { NOAA- } \\
\text { NCEP }\end{array}$ & $\begin{array}{l}4-18 \\
k m\end{array}$ & Daily & $\mathrm{D}$ & $\begin{array}{l}\text { NCEP } \\
\text { GFS ( 40 } \\
\mathrm{km})\end{array}$ & Daily & Daily & $0, \xi$ \\
\hline TOPAZ & HyCOM & $\begin{array}{l}\text { Norwegian } \\
\text { Met Office } \\
\text { (MET) }\end{array}$ & $12 \mathrm{~km}$ & Daily & $\mathrm{D}$ & $\begin{array}{l}\text { ECMWF } \\
\text { IFS ( 16 } \\
\mathrm{km})\end{array}$ & Weekly & Daily & 0 \\
\hline $\begin{array}{l}\text { FOAM- } \\
\text { NATL12 }\end{array}$ & NEMO & Met Office & $9 \mathrm{~km}$ & Daily & $\mathrm{D}$ & $\begin{array}{l}\text { UM } \\
\text { Global } \\
(\sim 25 \mathrm{~km})\end{array}$ & Daily & Daily & 0 \\
\hline $\begin{array}{l}\text { Mercator } \\
\text { ORCA12 }\end{array}$ & NEMO & $\begin{array}{l}\text { Mercator, } \\
\text { CMEMS }\end{array}$ & $9 \mathrm{~km}$ & Daily & $\mathrm{D}$ & $\begin{array}{l}\text { ECMWF } \\
\text { IFS ( 16 } \\
\mathrm{km})\end{array}$ & Weekly & Daily & $\mathrm{O}$ \\
\hline $\begin{array}{l}\text { FOAM- } \\
\text { ORCA025 }\end{array}$ & NEMO & Met Office & $9 \mathrm{~km}$ & Daily & $\mathrm{D}$ & $\begin{array}{l}\text { UM } \\
\text { Global } \\
(\sim 25 \mathrm{~km})\end{array}$ & Daily & Daily & 0 \\
\hline $\begin{array}{l}\text { Global } \\
\text { RTOFS }\end{array}$ & HyCOM & $\begin{array}{l}\text { NOAA- } \\
\text { NCEP }\end{array}$ & $9 \mathrm{~km}$ & Daily & $\mathrm{D}$ & $\begin{array}{l}\text { NCEP } \\
\text { GFS ( 40 } \\
\mathrm{km})\end{array}$ & Daily & Daily & 0 \\
\hline
\end{tabular}

Table 1: Summary of operational hydrodynamics models available for forcing deepwater oil spill forecasts. CMEMS is the European Commission's Copernicus Marine Environment Monitoring Service. ${ }^{1}$ Key to notes: $\mathrm{O}=$ Operational, $\mathrm{S}=\mathrm{S}$-coordinates, for resolving slope features, $\xi=$ tidal model, $\mathrm{P}=$ includes atmospheric pressure. 


\section{FIGURE LEGENDS:}

Figure 1: a) map of the Faroe-Shetland Channel (FSC) showing the established monitoring lines, Fair Isle - Munken (FIM; stations are triangles) and Nolso - Flugga (NOL; stations are squares). Station numbering is incremental SE to NW. Green dots are wells drilled in the UKCS*, stars illustrate the location of key oil installations and rhomboids show the location of areas of exploration referred to in the text; b) general geographical location of the focus area (black polygon), also showing the domain of 3 hydrodynamic models (see legend) referred to in the text.

* Source: UK Oil \& Gas Authority

Figure 2: Diagram summarising the general circulation features within the FSC. Arrows indicate the mean transport in the five main water masses (see text and Fig. 3): black, solid - NAW; dark grey, solid - MNAW; light grey, solid - MEIW; light grey, broken - NSAIW; black, broken - NSDW. Modified from Turrell et al. (1999).

Figure 3: distribution of water masses on a cross section of the FSC, with temperature contours. See text and Fig. 2 for water mass definitions.

Figure 4: a) time series of temperature profiles showing the vertical migration of temperature contours resulting from the passage of internal waves; b) optical backscatter, OBS (Volts; uncalibrated units), on two oceanographic transects (a) T1 and (b) T2 (see Hosegood et al., 2005 for full details).

Figure 5: satellite images of sea surface temperature in the FSC in (a) April and (b) August 1999; Reproduced from Sherwin et al. (2006).

Figure 6: Wind roses showing the 30 year ERI-Interim model wind speed $\left(\mathrm{m} \mathrm{s}^{-1}\right)$ monthly mean climatology at $60^{\circ} 20^{\prime} \mathrm{N}, 04^{\circ} 10^{\prime} \mathrm{W}$. The roses indicate the direction from which the wind comes from.

Figure 7: Wave roses showing the 30 year ERI-Interim model significant wave height of combined wind and swell waves $(\mathrm{m})$ monthly mean climatology at $60^{\circ} 20^{\prime} \mathrm{N}, 04^{\circ} 10^{\prime} \mathrm{W}$. The roses indicate the direction from which the waves come from.

Figure 8: Temperature time series recorded in-situ at the Celtic Sea shelf break in June 2012 at the position of mooring ST2 (upper panel) and model results for the same period (bottom panel).

Figure 9: Density plot of particle positions within $200 \mathrm{~m}$ of the seabed following monthly releases across the water column at a location in the FSC and spanning the period January 1994 - December 2009. Particle densities are shown in three depth bands of releases: top) $10-450 \mathrm{~m}$; middle) $500-$ $950 \mathrm{~m}$; bottom) 1000 - $1500 \mathrm{~m}$. Particle decay was effected using a simple decay algorithm, and drift was terminated on reaching $10 \%$ of the initial 'whole' state (Main et al., 2017).

Figure 10: Comparison of drifter data against trajectories of virtual drifters advected by surface currents from two different resolution models (Nordic4 and NorKyst800; see Section 3.3) off the Norwegian coast.

Figure 11: Marine Oil Snow (MOS) aggregate formed in a roller-bottle experiment containing seawater, Macondo crude oil and oil-degrading bacteria. 


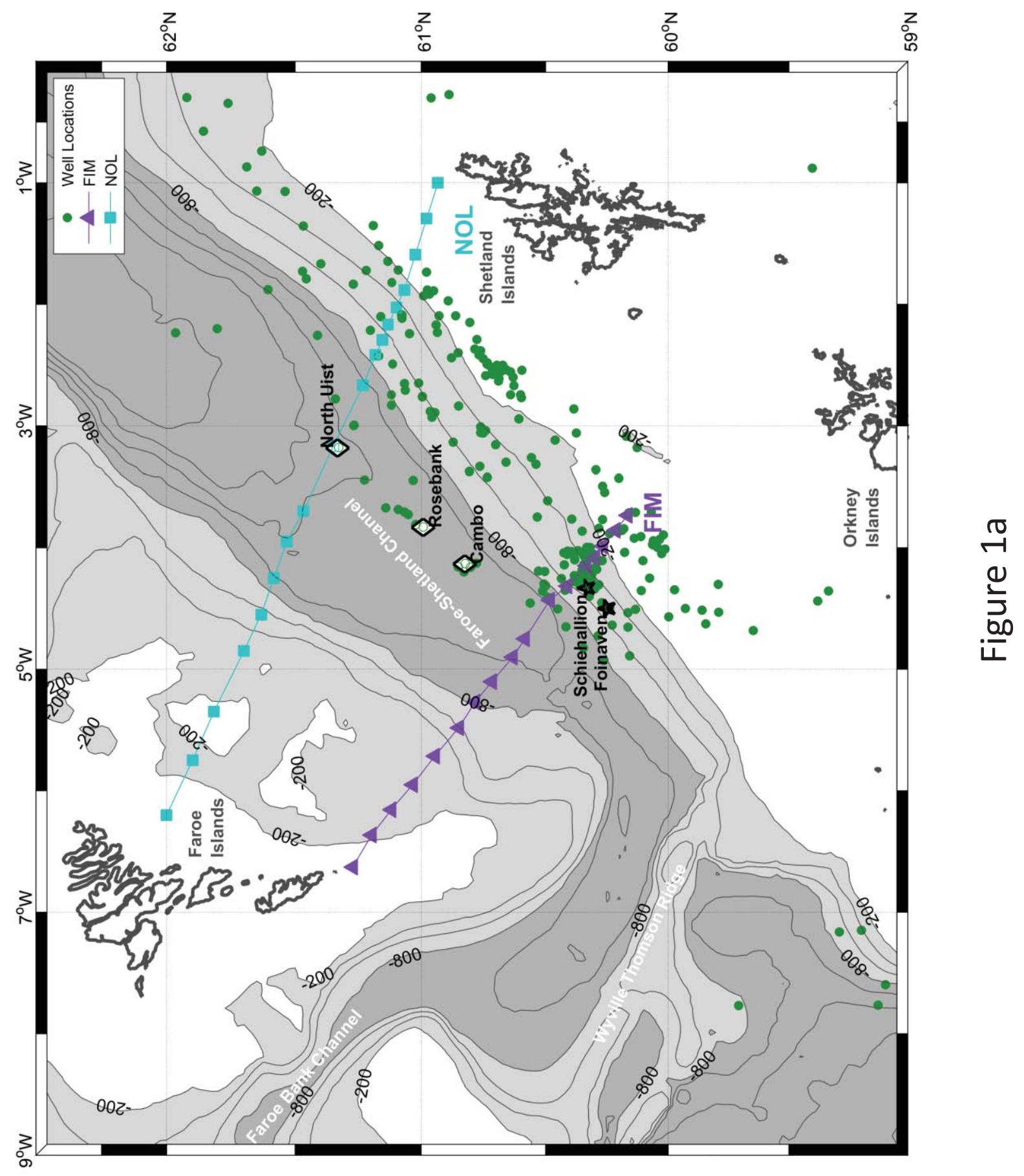



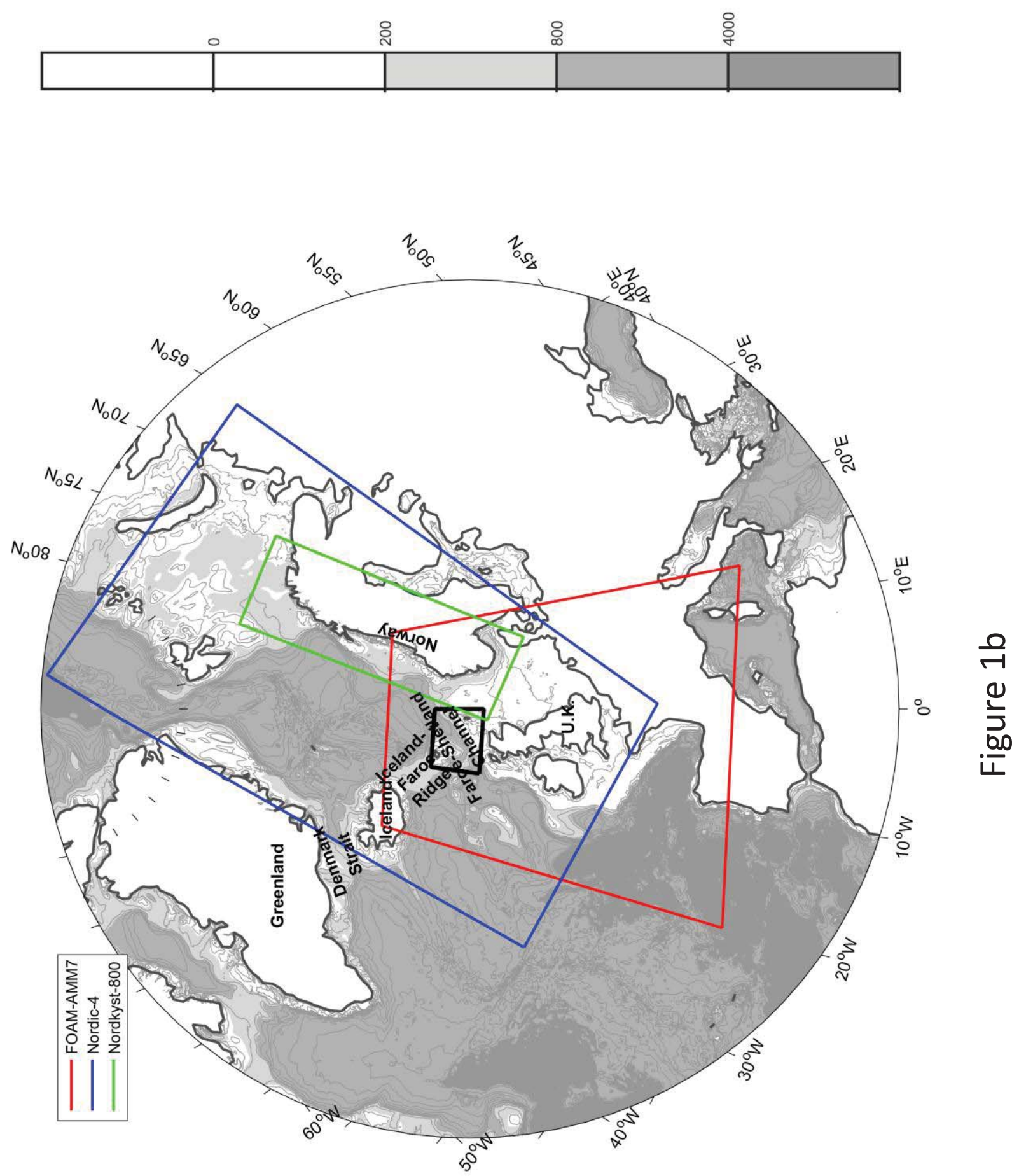


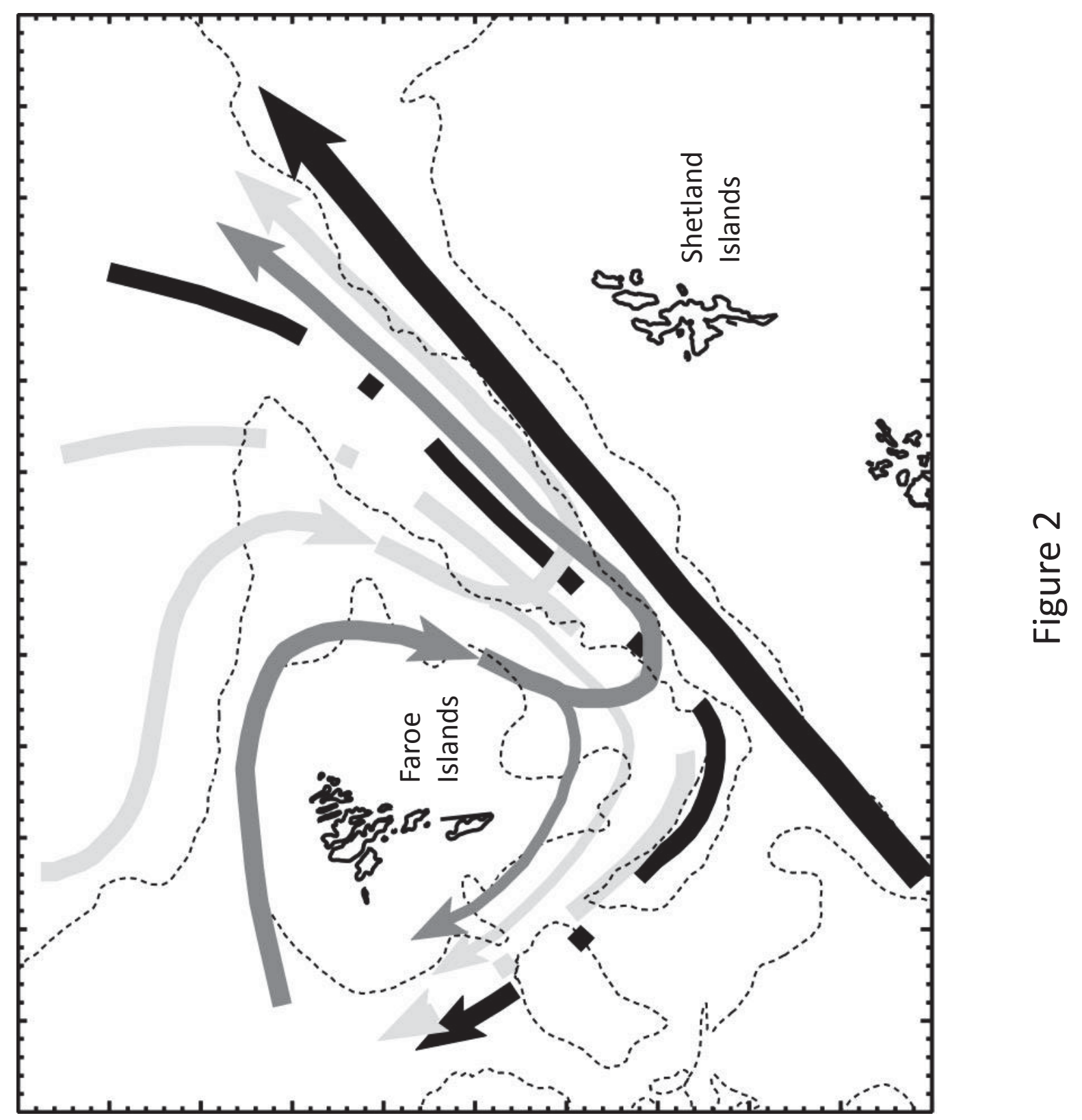


$\frac{\amalg}{\frac{\square}{\triangleright}}$

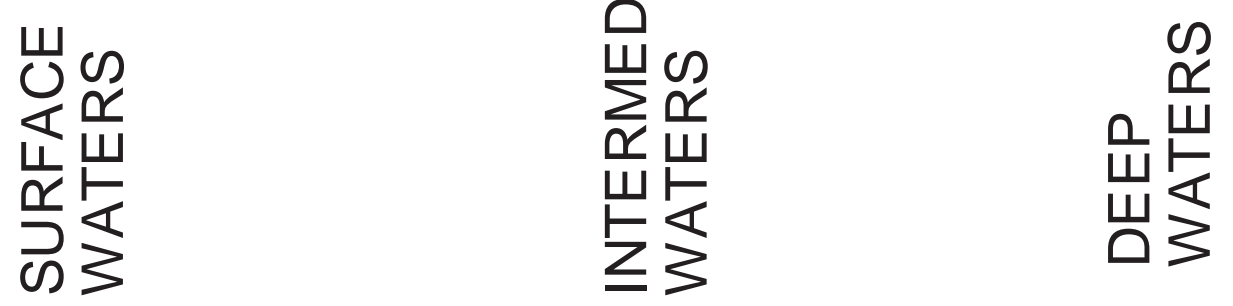
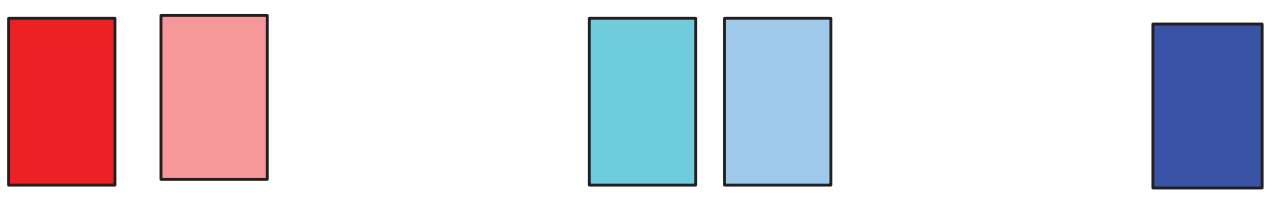

$\frac{E}{\frac{E}{8}}$
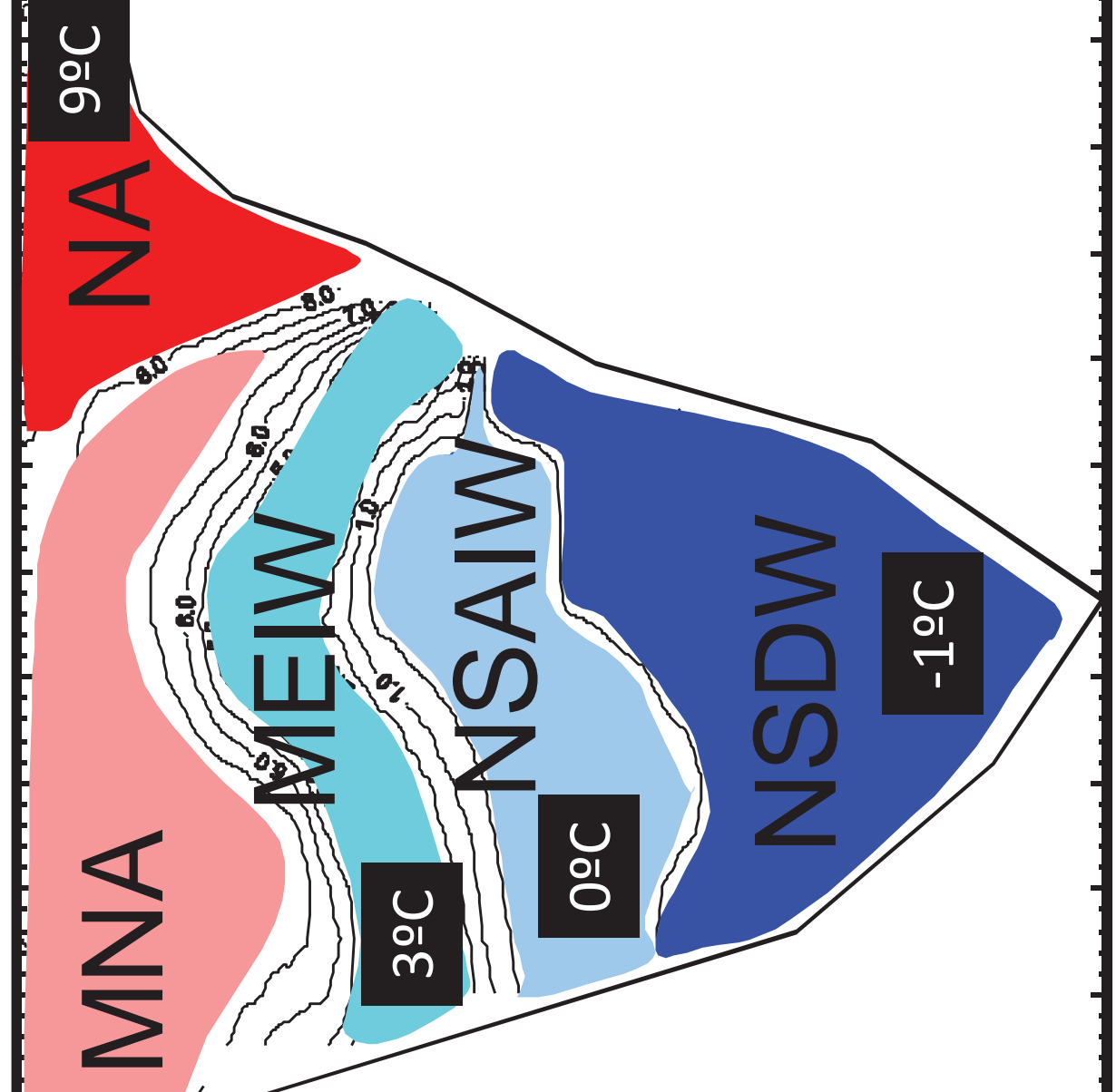

U

이

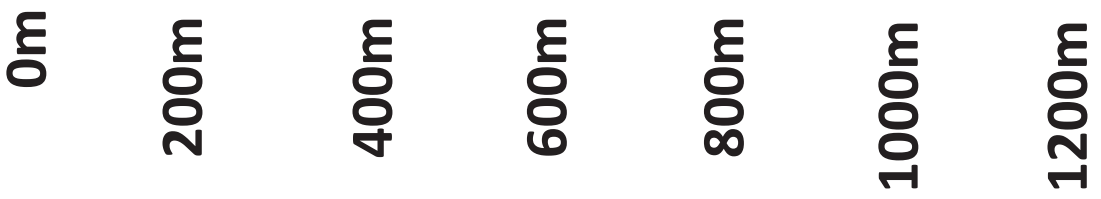

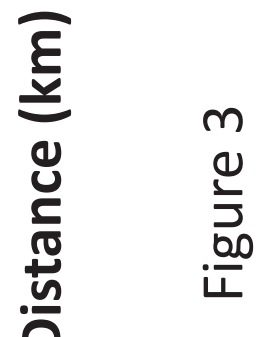




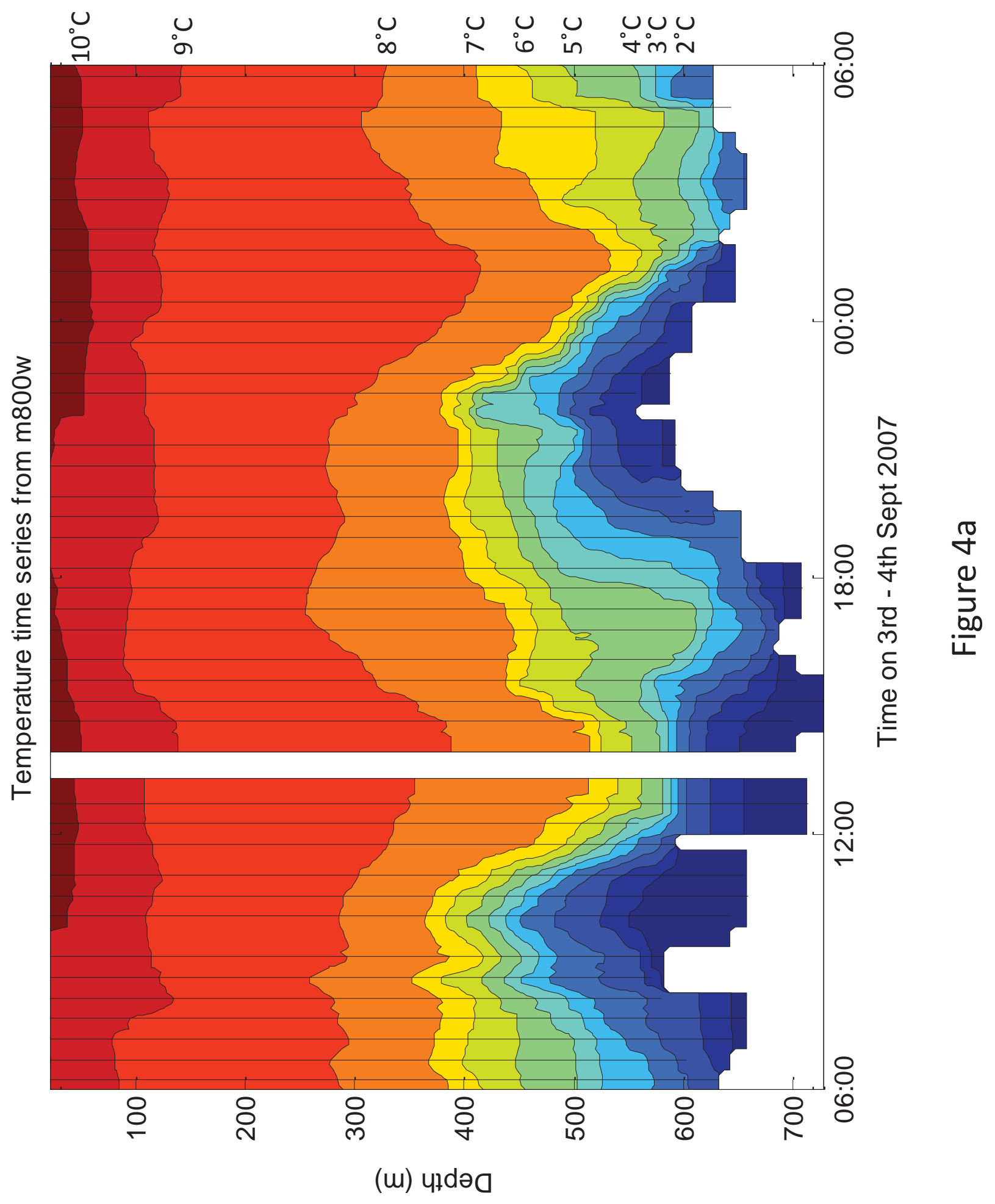




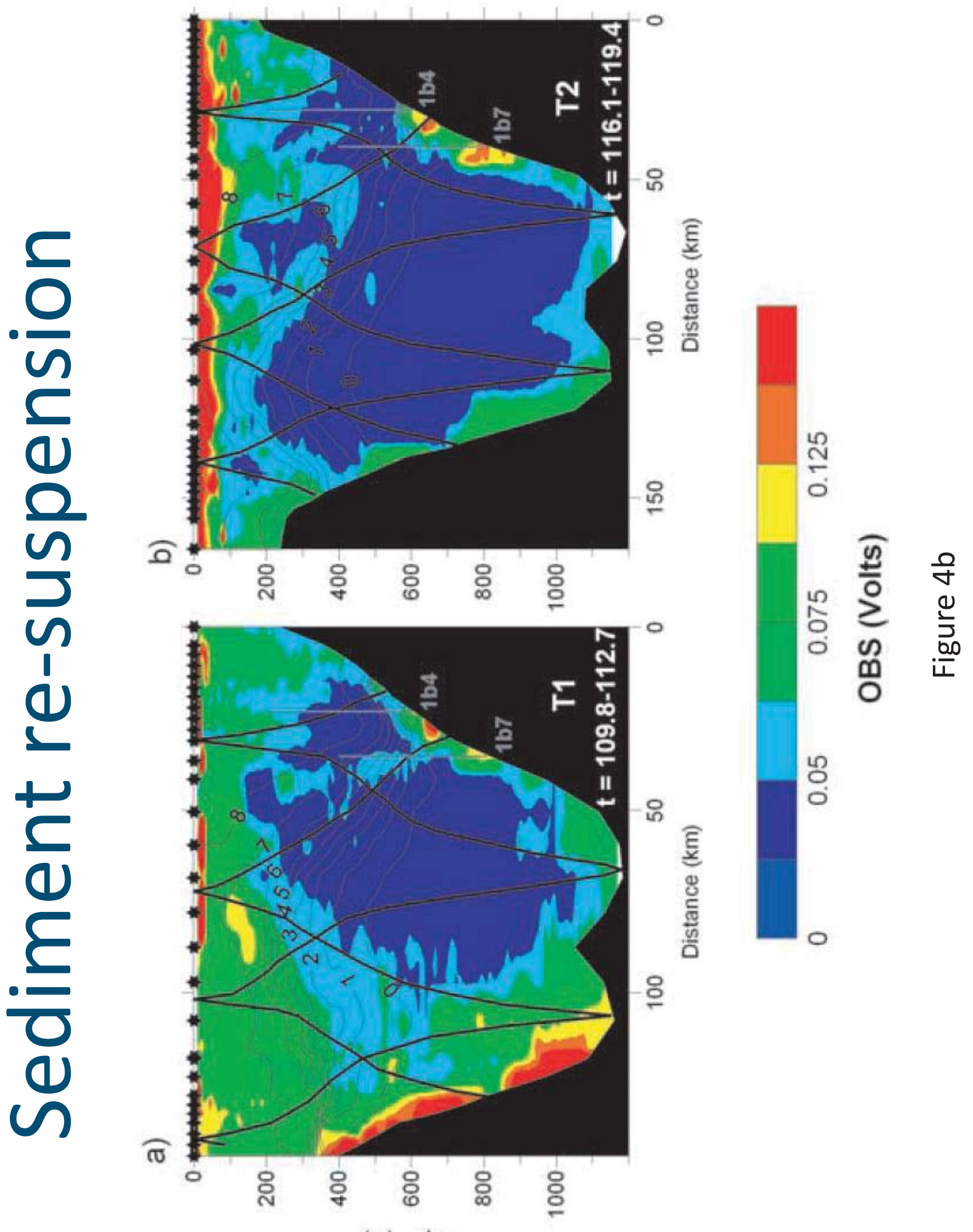

(ui) undea 

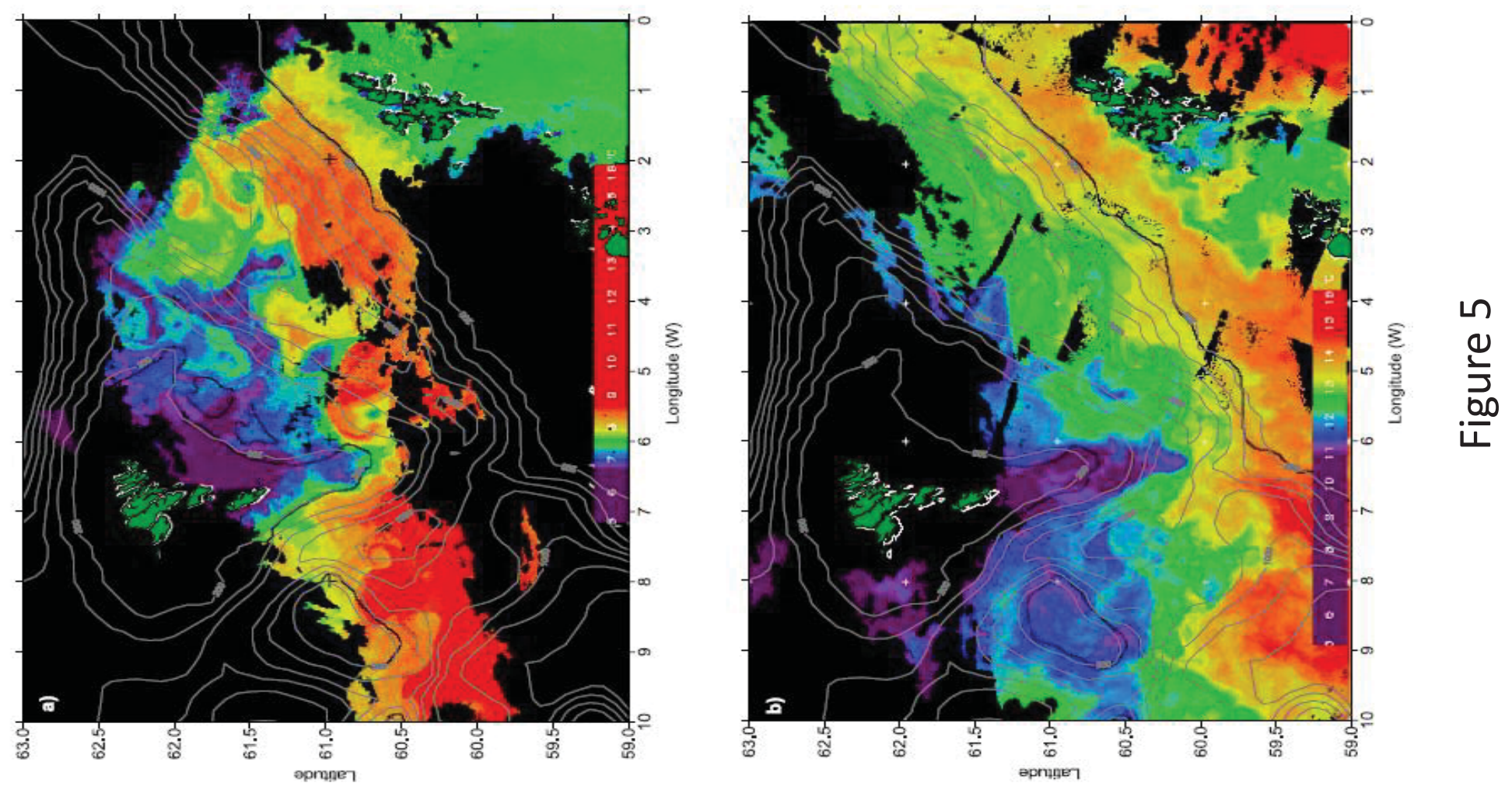


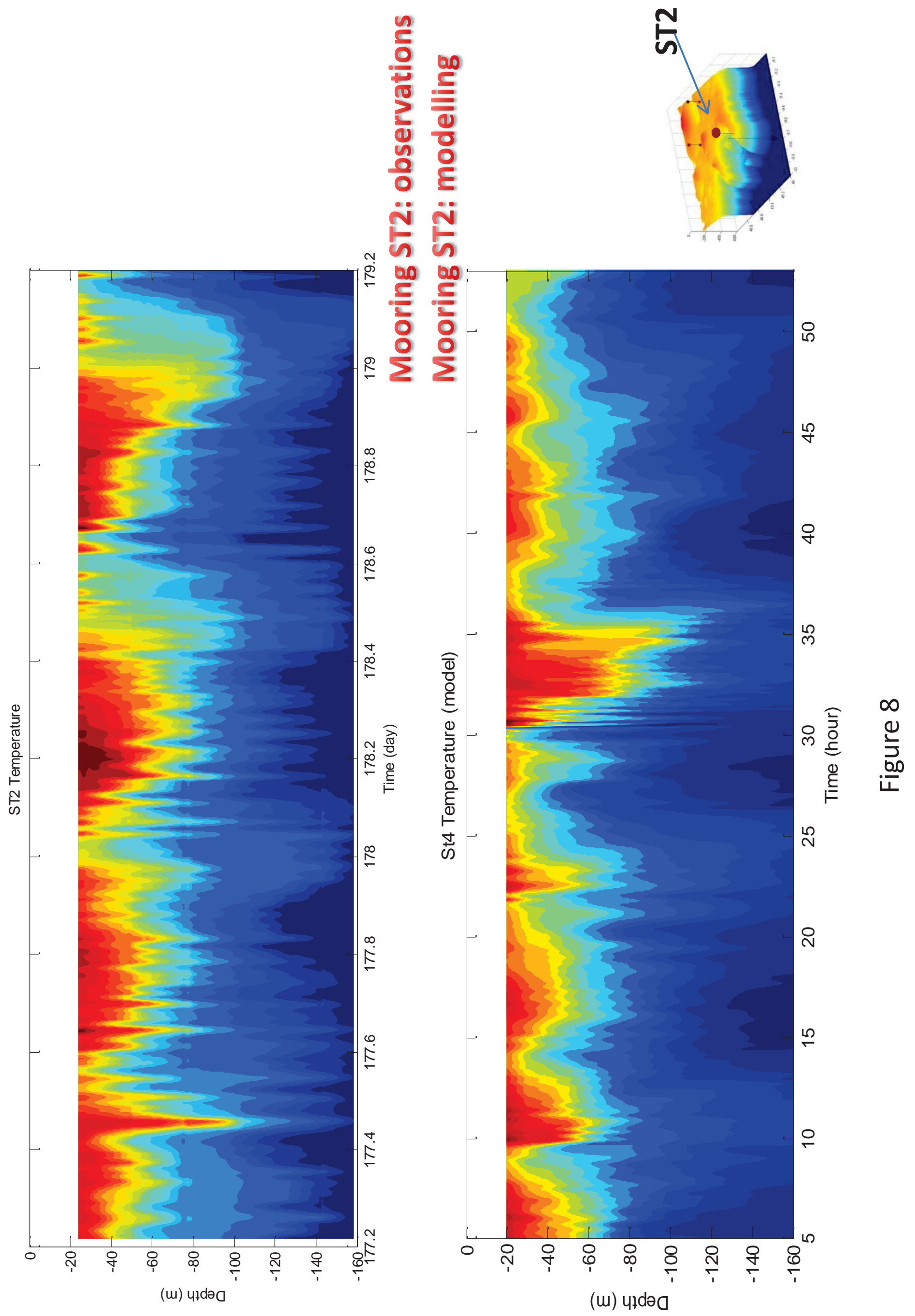


ఏำ

흘 웅응 -

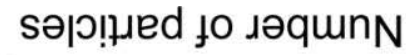

음웅-

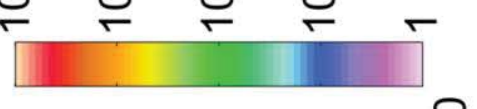

홍을 -
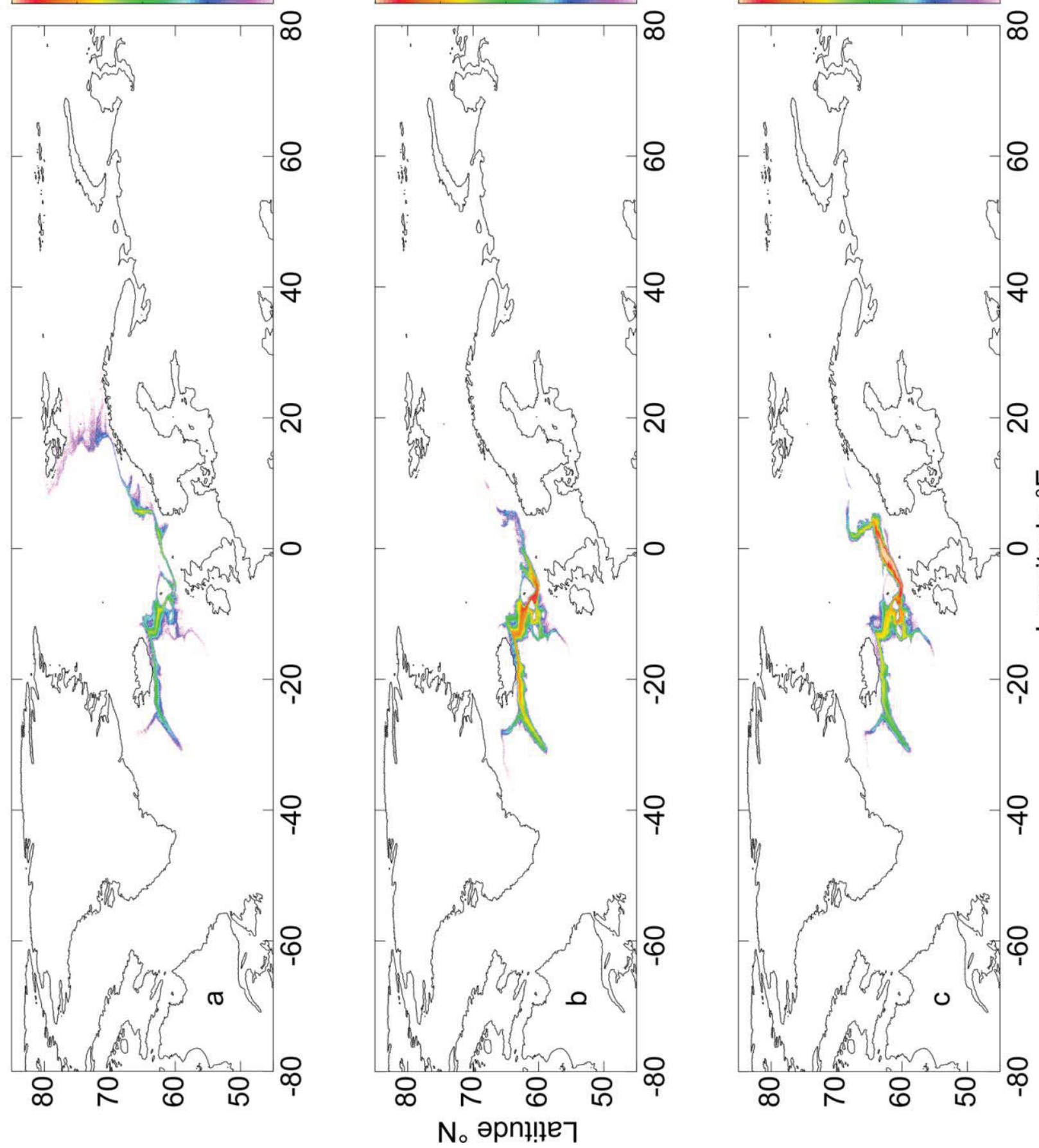

:

q

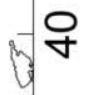

$\therefore$

๙

움

औำ

No әрni!ฺएา 


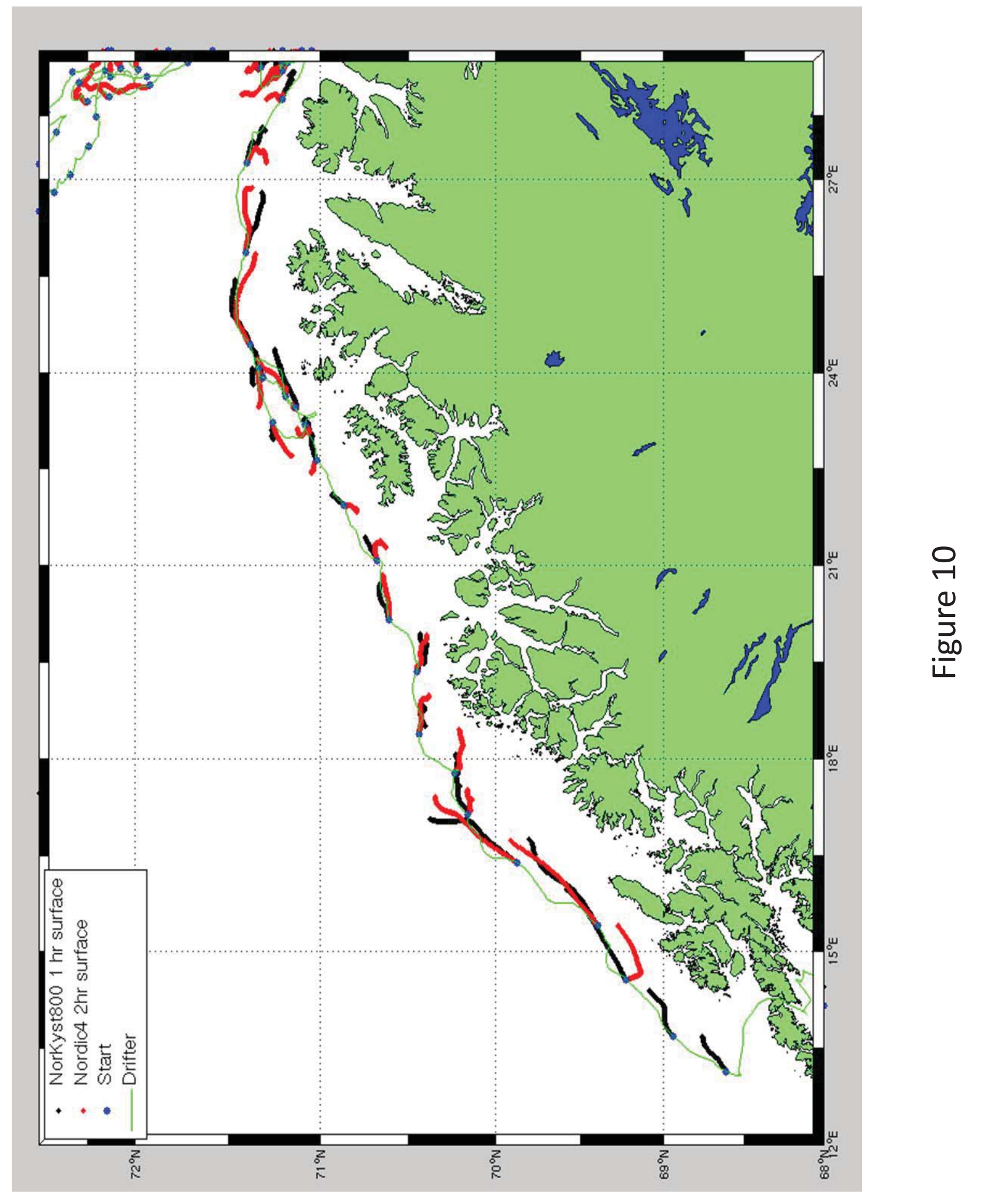




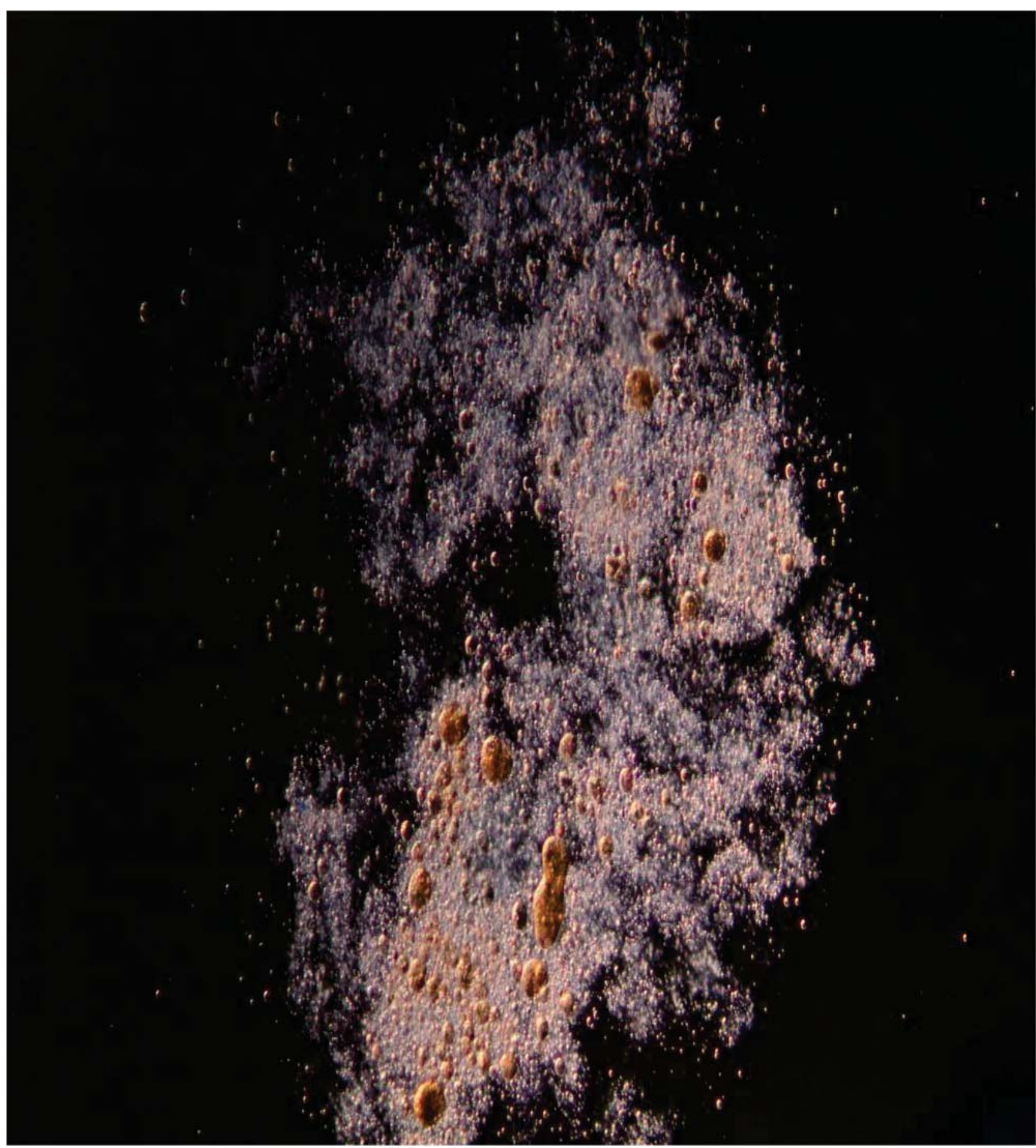

엄
$\frac{1}{2}$
$\frac{0}{1}$ 